\title{
Self-Assembly of Ternary Particles for Tough Colloidal Crystals with Vivid Structure Colors
}

\author{
Binfu Bao, ${ }^{1}$ Duo Liu, ${ }^{1}$ Youyou Yang, ${ }^{1}$ Zhehong Shen, ${ }^{1}$ and Bo You ${ }^{2}$ \\ ${ }^{1}$ Engineering Department of Zhejiang Agriculture and Forestry University, Lin'an, Hangzhou 311300, China \\ ${ }^{2}$ Department of Materials Science, Fudan University, Shanghai 20043, China \\ Correspondence should be addressed to Zhehong Shen; zhehong.shen@vip.163.com and Bo You; boyou2004@yahoo.com
}

Received 4 May 2013; Accepted 3 June 2013

Academic Editor: Amir Kajbafvala

Copyright (C) 2013 Binfu Bao et al. This is an open access article distributed under the Creative Commons Attribution License, which permits unrestricted use, distribution, and reproduction in any medium, provided the original work is properly cited.

Self-assembly of colloidal spheres is the most frequently used method for structural colors, but the chroma of the structural colors is usually so low that people cannot observe it under natural conditions. This paper presents a facile method for fabrications of vivid structural colors by doping carbon black into the self-assembly of colloidal polymer spheres and nanosilica particles. This approach can generate very gorgeous structural colors which can be very easily seen under natural conditions. The fabrication conditions for the self-assembly of composite dispersions of polymer/silica/carbon black were optimized to obtain colloidal crystals with vivid colors. Thus, robust mechanical properties, large-scale, and brilliant structural colors can guarantee the obtained crystal films to find practical applications, which are demonstrated by the fact that the successful applications of structural colors beautify the original simple and tedious surface of bamboo strand board (BSB).

\section{Introduction}

Photonic crystal has been the focus in material science and technology because of its manipulations of photon propagation and promising applications in communication, sensor and detector, coating, and displays [1-13]. Manufacture of some dyes and pigments usually causes pollutions and energy loss. Furthermore, some dyes and pigments are toxic, nondegradable, and fading. Therefore, structural colors from photonic crystals have obtained increasing attention, because of bright colors, durability and environmental friendliness. Self-assembly of colloidal spheres into photonic crystals has been one of the most widely used methods since this strategy is relatively simple and cost efficient [14-24]. The fabrication of robust colloidal crystals for structural color by self-assembly of soft polymer/silica particles is novel and facile works. It is carried out at room temperature without additional equipment compared with other methods for structural colors $[23,24]$. Though self-assembly of colloidal spheres into photonic crystals is simple, mass producible, and the least expensive, it is inevitable to introduce random defects, such as missing particles, uncontrolled orientation, mixture of phases, and dislocations during the self-assembly processes $[16,25]$. Theses defects decrease the reflectivity in the stop band region and scatter light outside the stop band. Thus, the light we usually observe not only contains the wavelength corresponding to the expected color unveiled by the stop band, but also unwanted wavelength outside the stop band. As a result, the color from the colloidal crystal with defects is not as vivid as natural opals. It is not striking or brilliant under natural conditions. On occasion, only an experienced man could detect its color at a certain angle to light source [26], which limits its applications in coatings, cosmetics, decorations, textiles, and sensors [27, 28].

In order to make the interference color pure and highly saturated, Wang et al. [27] coated thin anodic aluminum oxide (AAO) films on an $\mathrm{Al}$ substrate uniformly with carbon by chemical vapor deposition. The saturation of interference color is substantially enhanced as a result of the carbon deposited on the inner walls of the nanochannels of the AAO film, which efficiently screens the reflected light from AAO$\mathrm{Al}$ interface. Pursiainen et al. [28] mixed carbon with coreshell polymer sphere precursor. The precursor consisted of a hard crosslinked polystyrene (PS) sphere coated with a thin polymethyl-methacrylate (PMMA) interlayer anchored by the outer shell composed of soft polyethylacrylate (PEA). 
Then polymer melt compression was used to fabricate polymer opals. The visual appearance of the elastomeric opals changes quite remarkably from milky white to intense green. Inspired by peacock feathers, which contain small amount of melanin rods in three-dimensional periodic structures for brilliant colors [29], we successfully fabricated a robust and large-scale colloidal crystal (CC) film with enhanced and tunable vivid structural colors [30]. In comparison to previous techniques, the primary differences and advantages of this approach are as follows. (i) The polymer crystal films with vivid colors are easily obtained directly by drying at room temperature. Neither tedious work nor special equipment or high temperature is needed. Other approaches to dope carbon black at high temperature limited applications on the substrate that could not bear high temperature such as BSB. (ii) The polymer colloids are readily obtained, and the resulting photonic crystal films are robust, which endow the substrates not only with brilliant colors but also with good strength such as hardness. (iii) This method can be used for massive production of polymer colorful films of any size from square centimeters to square meters. In this paper, the treated carbon black had high surface charge, which is not only important to prevent carbon black from coagulating, but is also important to form periodic structures. Self-assembly of three colloidal particles into ternary periodic structures has complicated interactions between particles, which differ from other carbon black doping in the assembly mechanism and is not researched by other groups. So the fabrication factors differs greatly from the previous researches $[26,30]$. In order to obtain the optimal growth conditions for high crystalline quality, in this paper, the effect of carbon black properties, evaporation temperature, relative humidity $(\mathrm{RH})$, and silica content on polymer films are researched systematically by controlled self-assembly process to study the action mechanism. It is not studied by other groups, which provides a good basis for commercialization.

\section{Experimental Section}

2.1. Materials. Butyl acrylate (BA), styrene (St), acrylic acid (AA), ammonium persulfate (APS), sulfuric acid, and nitric acid were purchased from Shanghai Chemical Reagent Co. (China). Silica sol. ( $20 \mathrm{~nm}, \mathrm{pH}=3,34 \mathrm{wt} \%$ of solid content) was provided by Eka Chemicals Co. (Sweden). Allyloxy hydroxypropyl sodium sulphonate (HAPS, $40 \mathrm{wt} \%$ of solid content in aqueous solution) was kindly donated by Shuangjian Trading Co., Ltd. (China). Carbon black was donated by Carbot Co. Ltd. Deionized water was used in all the polymerizations. All the chemical reagents were used without further purification.

2.2. Synthesis of Soft Colloidal Polymer Spheres. A surfactantfree emulsion polymerization procedure was carried out as mentioned in the paper [23]. A typical process was described as follows: deionized water (95 g), HAPS (1.0 g), AA (2 g), BA $(20 \mathrm{~g})$, St $(20 \mathrm{~g})$, and APS $(0.25 \mathrm{~g})$ were added into a fournecked flask equipped with an $\mathrm{N}_{2}$ inlet, a reflux condenser, and a mechanical stirrer. The polymerization was carried out at $75-80^{\circ} \mathrm{C}$ for $10 \mathrm{~h}$ to obtain water-borne polymer latex with a solid content of $34 \mathrm{wt} \%$. The polymer latexes with various particle sizes were synthesized by controlling HAPS contents. The glass transition temperature of polymers is $23^{\circ} \mathrm{C}$ which was measured by DSC.

2.3. Treatment of Carbon Black (CB). Carbon black was blended with concentrated sulfuric acid for $12 \mathrm{~h}$, then centrifuged and washed with deionized water until the $\mathrm{pH}$ was near to 7 and dispersed in deionized water with $0.5 \mathrm{wt} \%$ of solid content. Bpc40 carbon black with $-25 \mathrm{mV}$ was used unless specifications were noted.

2.4. Preparation of Colloid Crystal Films with Carbon Black (CCB) and without Carbon Black (CCW). The polymer latexes were blended with colloidal silica and carbon black under vigorous were stirring for $2 \mathrm{~min}$ and ultrasonically treated for $2 \mathrm{~min}$ at room temperature to obtain nanocomposite polymer latexes. The typical weight ratios of silica and carbon black to polymer were 20 and $0.15 \%$, respectively, unless specifically noted.

2.5. The Controlled Fabrication of CCB Film. The glass substrate was cleaned in ethanol, acetone, and deionized water successively and dried in nitrogen gas. Then the dry glass substrate was put into the conditioner and cast with same volume of dispersions to insure the same thickness of all films. Figure 1 was the experiment setup for self-assembly in controlled temperature and relative humidity $(\mathrm{RH})$. A smart temperature and $\mathrm{RH}$ control system was employed to control the temperature and $\mathrm{RH}$ accurately. If $\mathrm{RH}$ in the conditioner was too low, the RH control system will start the evaporation system to let more vapor into the conditioner and improve $\mathrm{RH}$ to the preset level. If $\mathrm{RH}$ was too high, the $\mathrm{RH}$ control system will start to let out unnecessary vapor to keep RH at the preset level. By this control system, the temperature and $\mathrm{RH}$ in the conditioner will be adjusted accurately according to the predetermined level.

2.6. Characterization. The reflection spectra of CC films were taken using the beam spot of $0.04 \mathrm{~mm}^{2}$ in area and integral sphere fiber optic UV-Vis spectrometer (Ocean Optics, ST2000, Dunedin, FL, USA). The photos of CCB and CCW films were taken by Cannon Power Shot A 95. SEM images of the samples were obtained with a Philips XL 30 field emission microscope; all samples were coated with gold by sputtering prior to observations. The size and size distribution of polymer spheres were measured by $\mathrm{N} 4$ Plus particle size analyzer. The color differences of CCB and CCW films were measured by a spectrophotometer (CM700d, Konica Minolta Sensing Inc., Japan) according to Commission International d'Eclairage (CIE) LAB color scale. The LAB system has a lightness scale $L$ and opponent color axes for redness-greenness versus yellowness-blueness, designated $A$ and $B$, respectively. Each color can be represented by a unique point in three-dimensional coordinate used in the LAB system. The $L$ value characterizes the brightness of the color and range between 0 (dark) and 100 (light). The $A$ and 


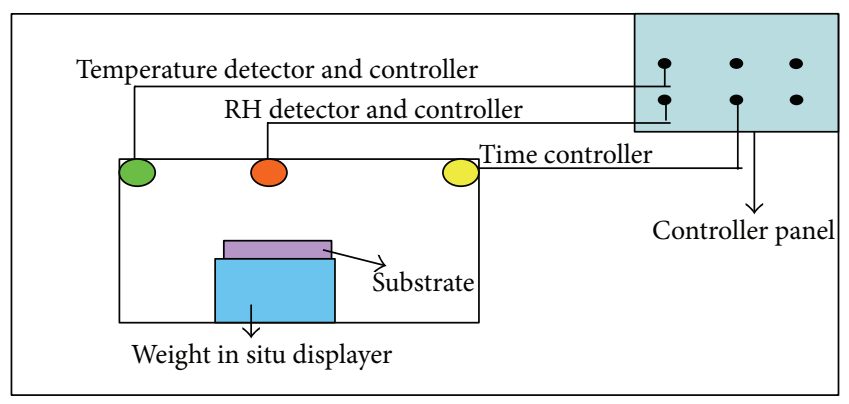

FIGURE 1: Experiment setup of the controlled self-assembly.

$B$ values are the chroma coordinates and characterize the hue and chroma factors. The $A$ axis is red on the positive side and green on the negative side; the $B$ axis is yellow on the positive side and blue on the negative side. The higher the $A$ and $B$ values, the stronger the colors.

\section{Results and Discussion}

3.1. The Mechanism of Color Purifications. The colloidal films from composite dispersions of polymer/silica and polymer/silica/carbon black are fabricated by the control method. The reflection spectra in Figure 2 show that the peak positions of CCB and CCW films are $677 \mathrm{~nm}$ and $666 \mathrm{~nm}$, respectively, with the size of polymer spheres as $301 \mathrm{~nm}$. According to Bragg diffraction law (1), peak positions have relationships with the effective index $\bar{n}$ and the distance $d$ between [111] crystal planes calculated by $d=\sqrt{2 / 3} D$, where $D$ is the diameter of the polymer spheres. When carbon black is doped, the effective index $\bar{n}$ has increased from 1.439 to 1.443 according to (2), while $d$ remains unchanged for the same polymer spheres. According to (1), the calculated peak position of CCB film is $709 \mathrm{~nm}$, which red-shifts about $2 \mathrm{~nm}$ compared with $707 \mathrm{~nm}$ for CCW film. The calculated peak positions are in rough agreement with the observation peak positions. The blue shifts of observation peak positions from calculated peak positions are caused by the shrinkage of soft polymer spheres during self-assembly. Consider

$$
\lambda=2 \bar{n} d \sqrt{1-\frac{1}{\bar{n}^{2}} \sin ^{2} \theta},
$$

$\bar{n}$

$$
=\sqrt{f_{\text {polymer }} n_{\text {polymer }}^{2}+f_{\left(\mathrm{SiO}_{2}+\text { air }+ \text { carbonblack }\right)} n_{\left(\mathrm{SiO}_{2}+\text { air }+ \text { carbonblack }\right)}{ }^{2}} .
$$

The perfect colloidal crystal film with few defects has pure colors because it has high reflectivity in the stop band region while low reflectivity outside the stop band [31]. The colloidal crystal film especially assembled from colloidal spheres has inevitable defects such as vacancy and dislocations, which makes the reflectivity in the stop band region low while the reflectivity outside the stop band high. The increased reflectivity of unwanted photons outside the stop band will reduce the purity of the color unveiled by the stop band.

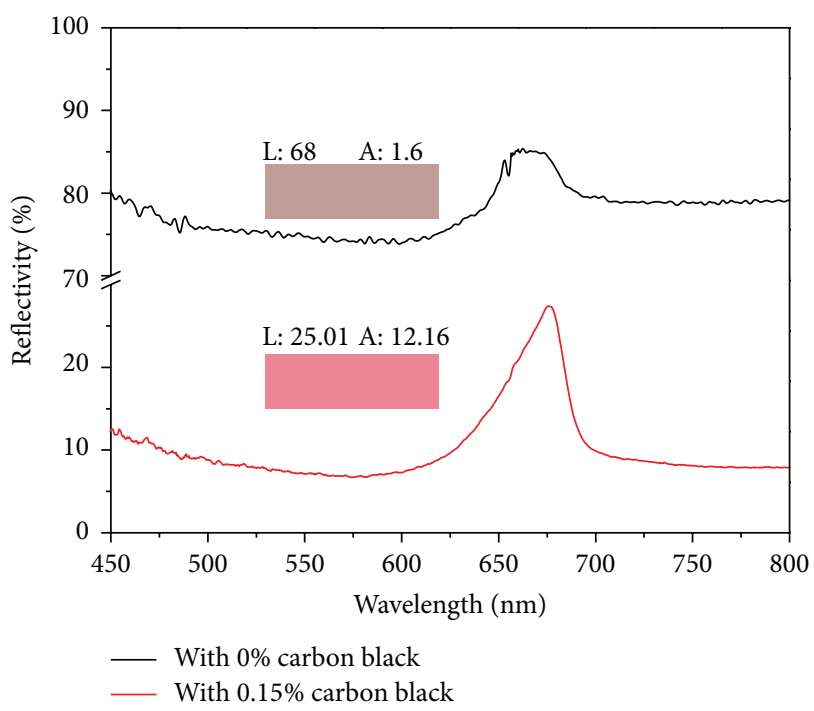

FIGURE 2: Reflection spectra of CCB and CCW films.

The reflectivity in the stop band region of CCW film is $85 \%$ with $80 \%$ reflectivity outside the stop band. So the reflection contrast is about $5 \%$. The reflectivity in the stop band region of CCB film is $27 \%$ with $8 \%$ outside the stop band. The reflectivity in the stop band region reduces by $58 \%$ while the reflectivity outside the stop band reduces by $72 \%$. This means that carbon black absorbs $58 \%$ photons in the stop band region and $72 \%$ photons outside the stop band. The reduction of the reflectivity in the stop band region will reduce the purifications of the colors, while the reduction of the reflectivity outside the stop band will increase the purifications of the colors. We use the reflection contrast or peak height as an important index to evaluate the overall effect of the photon reflectivity on the purity of the colors. The higher the peak height, the less the unwanted photons and the purer the colors unveiled by stop band. The reflection contrast of CCB films is about $19 \%$. The reflection contrast of CCB film increases by $14 \%$ compared with $5 \%$ of CCW film. So the colors of CCB film are purer than of CCW films, which are proved by the inserted pictures of CCB and CCW films as shown in Figure 2. The chroma factor of CCB films is 12.16, higher than the 1.60 of CCW films. The mechanism that carbon black could purify the colors of colloidal crystal films is that the reflection contrast is improved by carbon black doping because of its less absorption of photons in the stop band region than outside the stop band.

To verify this, we simulate crystal films with $301 \mathrm{~nm}$ polymer spheres using a modified Lay-KKR method [32]. This can simulate reflection and absorption coefficients of light using a slab of three-dimensional photonic crystals. The photonic crystal consists of a stack of slices parallel to a given surface. These slices may consist of two components. Each of them can be either a homogeneous plate or a multilayer of spherical particles of given periodicity parallel to the surface. The refractive index of each component material can be complex. The original code of Lay-KKR 
method can be downloaded from the website of the computer physics communication program library. In the simulation, the effective refractive indexes of the matrix and polymer spheres are 1.15 and 1.53, according to this experiment. For the simulated absorption of carbon black particles in the matrix, the imaginary part of refractive index of matrix is 0.15 . Thus, the theoretical reflection and absorption spectra can be shown in Figure 3. The theoretical reflection spectra can match the experimental spectra very well, but they also differ from the actual absorption spectra of carbon black. It can be inferred that carbon black in the crystal films has a very little ability to absorb photons in the stop band region but has a strong absorption outside it. It is this characteristic that allows the doped carbon black to restrain the light scattering of unwanted wavelengths and retain low absorption in the stop band. This can ensure that the carbon-black-doped crystal films have strong reflectance in the stop band, enhancing the chroma factor of structural colors. Figure 4 is the SEM images of CCW and CCB films, respectively. The polymer spheres self-assemble into orderly structures with silica and carbon black filled in the interstices between polymer spheres or located around the polymer spheres, which could be seen in the inserted pictures in Figure 4. It demonstrates the long range crystalline orders in CCW and CCB films.

3.2. The Application of the Vivid Structure Color. Bamboo strand board (BSB) is made of strand which was produced from bamboo by rolling. It has good physical and mechanical properties, which could take place of wood in many applications such as interior flooring, furniture, and decorations. Figure 5(a) is the unfinished BSB with simple and tedious surface, which limits its applications in interior decorations. Figures 5(b) and 5(c) are BSB finished with structural colors from CCW and CCB films under natural conditions. Though the color of BSB could be obtained easily by CCW films, it has low chrome value of 2.56 under natural conditions. The color is so weak that it almost could not be observed under natural conditions. By carbon black doping, the colors of BSB have high saturations with chrome value of 10.49 under natural conditions, which could be used in interior decorations and furniture making. According to cross-cutting methods for the adhesion between coating films and substrates, the adhesion between CCB films and BSB are scale 2. The CCB films made from $\mathrm{P}(\mathrm{ST}-\mathrm{BA}-\mathrm{AA})$ have polar groups of $\mathrm{COOH}$, while $\mathrm{BSB}$ is rich in polar groups of $-\mathrm{OH}$. So the adhesion between $\mathrm{CCB}$ films and BSB is high because of molecular attractions such as hydrogen bonds and van der Waals forces. There are cell pits and other fissures on the surface of BSB. The polymer latex could seep into the BSB by capillary action and form the bonding nails between the film and $\mathrm{BSB}$, which is the other factor to contribute to the good adhesion. The CCB film presents not only vivid colors but also good mechanical properties with tensile strength, breaking elongation, and hardness as high as $3.05 \mathrm{MPa}, 358 \%$, and $2 \mathrm{H}$. Furthermore $\mathrm{BSB}$ has high modulus of rupture (MOR) of $130 \mathrm{MPa}$, which improves the bending strength of CCB film on it. So BSB is a suitable substrate for practical applications of structural colors.

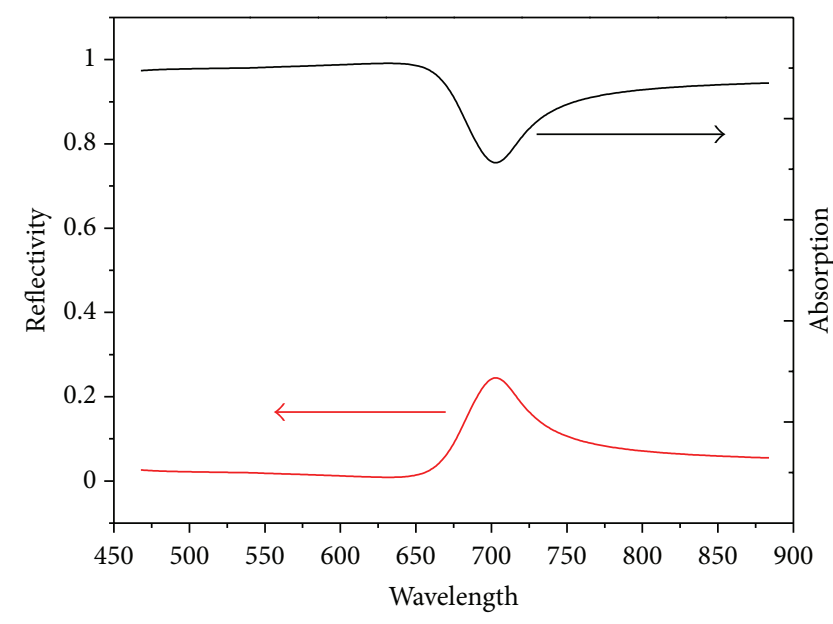

FIgURE 3: Theoretical simulated absorption and reflection spectra of polymer/silica/carbon black crystal films.

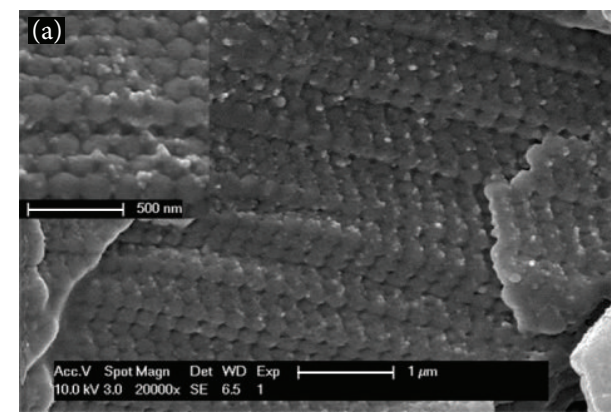

(a)

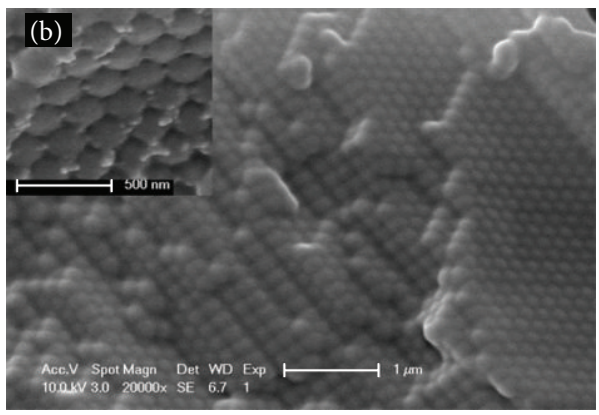

(b)

FIGURE 4: SEM images of colloidal crystal films (a) without carbon black and (b) with bpc40 carbon black.

3.3. The Effect of Carbon Black Properties on Polymer Films. Figure 6 and Table 1 show that three kinds of carbon black differed greatly in BET surface area and pore size distribution. The inset pore size distribution plot shows that pore size of vxc72 in Figure 6(a) ranges widely from $1 \mathrm{~nm}$ to $100 \mathrm{~nm}$, while the pore sizes of bpc 40 in Figure 6(b) and bpc20 in Figure 6(c) center on less than $10 \mathrm{~nm}$. This means that the pore sizes of bpc 40 and bpc 20 are in narrow size distribution compared with vxc72. The TEM images in Figure 7(a) show that, after pretreatment, vxc72 carbon black clusters and aggregates severely, while bpc 40 and bpc20 are dispersed as 


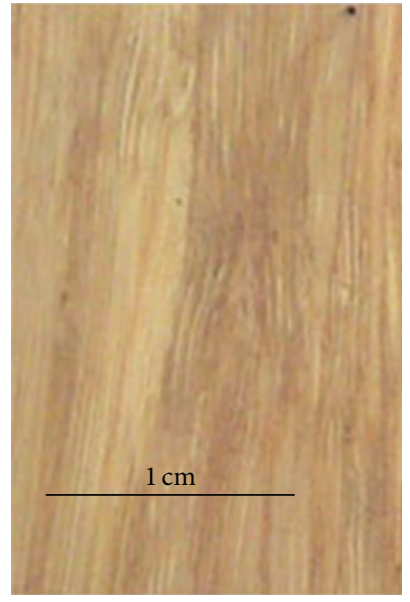

(a)

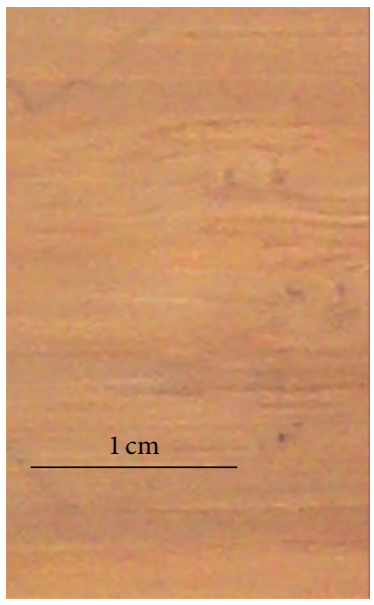

(b)

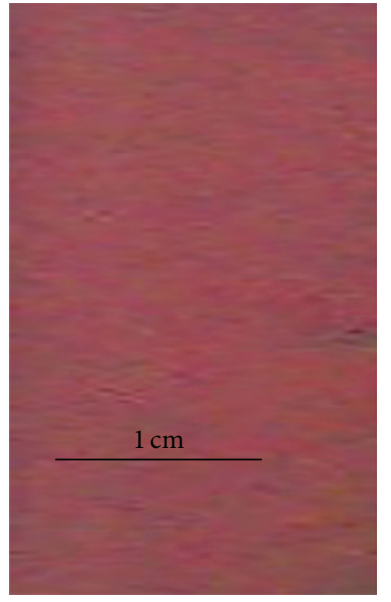

(c)

FIGURE 5: BSB (a) unfinished and finished with (b) CCW and (c) CCB films.

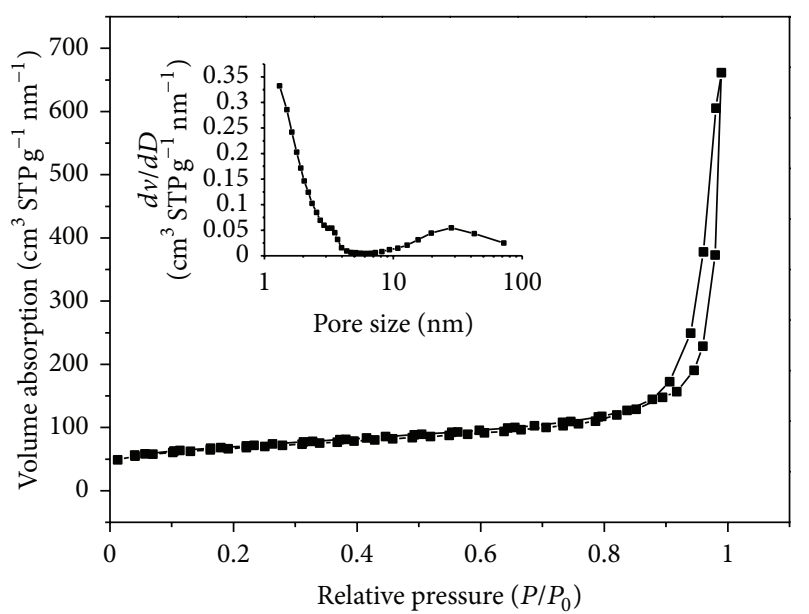

(a)

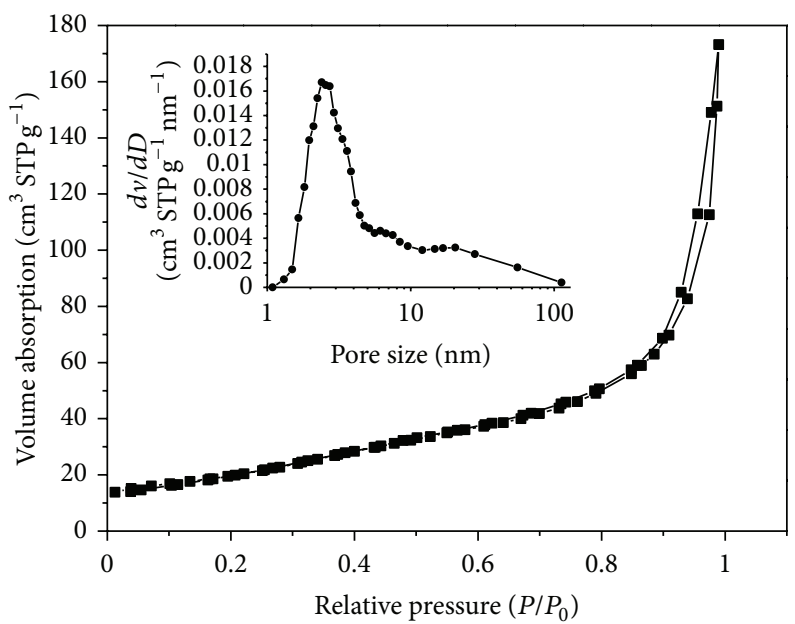

(b)

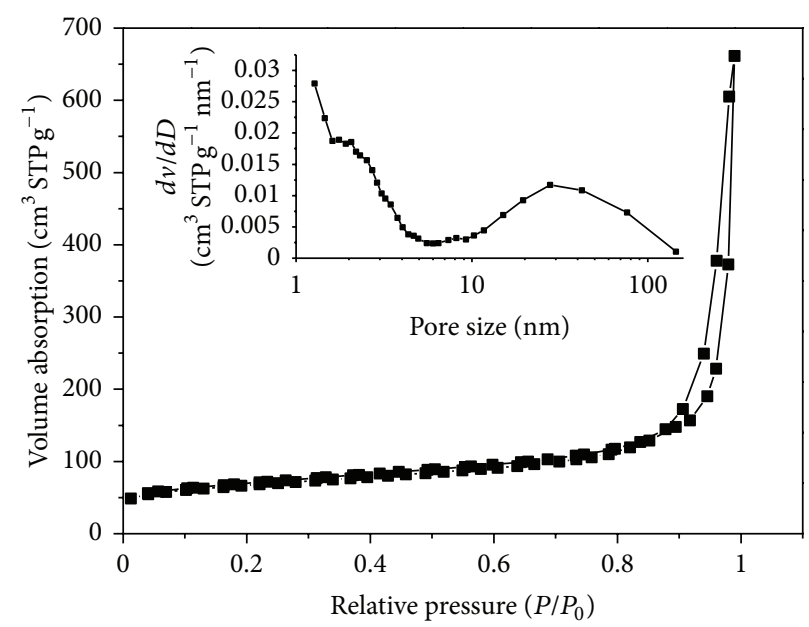

(c)

FIGURE 6: $\mathrm{N}_{2}$ adsorption-desorption isotherms of vxc72 in (a), bpc40 in (b), and bpc20 in (c). 
TABLE 1: Structural parameters of carbon black.

\begin{tabular}{lcccc}
\hline Sample & BET surface area $/ \mathrm{m}^{2} \mathrm{~g}^{-1}$ & Langmuir surface area $/ \mathrm{m}^{2} \mathrm{~g}^{-1}$ & Total pore volume $/ \mathrm{cm}^{3} \mathrm{STP}^{-1}$ & Average pore diameter $/ \mathrm{nm}$ \\
\hline vxc72 & 226.20 & 330.10 & 1.023 & 1.27 \\
bpc40 & 72.00 & 107.80 & 0.268 & 2.54 \\
bpc20 & 1365.00 & 1996.00 & 3.408 & 1.309 \\
\hline
\end{tabular}

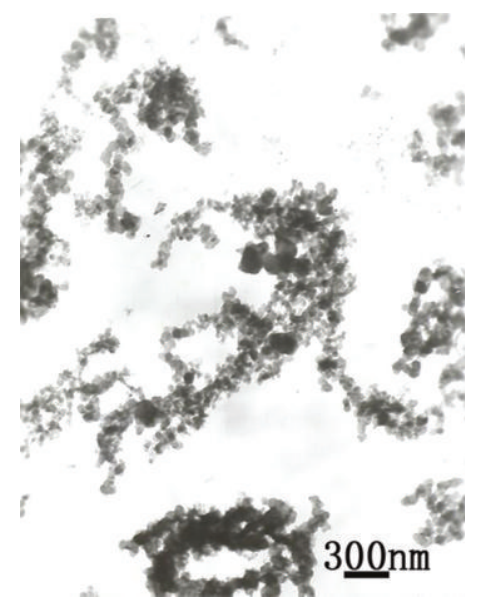

(a)

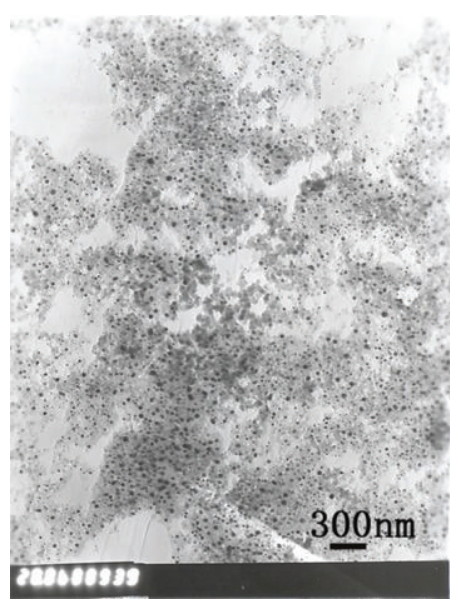

(b)

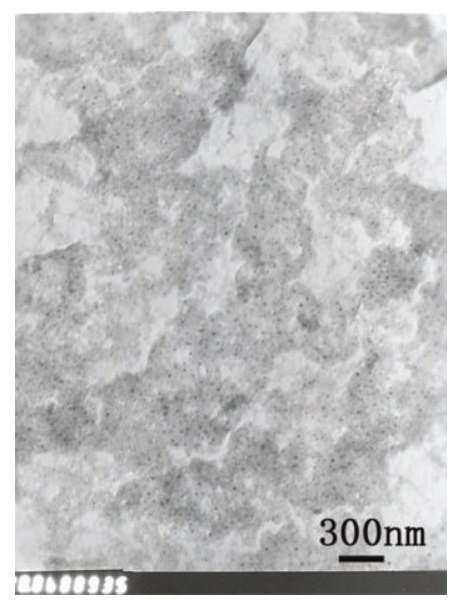

(c)

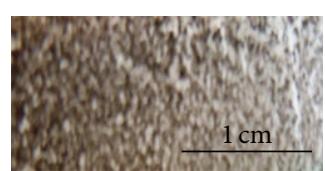

(d)

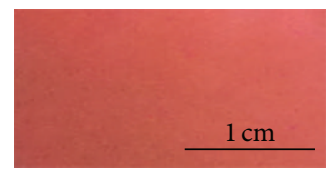

(e)

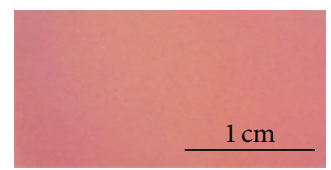

(f)

Figure 7: TEM images of vxc72 in (a), bpc40 in (b), and bpc20 in (c); the scales bars are $300 \mathrm{~nm}$; photos of polymer films with vxc72 in (d), bpc40 in (e), and bpc20 in (f).

shown in Figures 7(b) and 7(c). When $0.15 \%$ weight of carbon black is mixed with the dispersions of polymer/silica to selfassemble, vxc72 segregated from the film, and no iridescent color existed as shown in Figure 7(d). Bpc40 and bpc20 selfassembled with the dispersions of polymer/silica and formed vivid iridescent colors as shown in Figures 7(e) and 7(f). The SEM images prove long range disorders in the polymer film with vxc72 as shown in Figure 8(a) and periodic structures in the polymer film with bpc40 and bpc20 as shown in Figures 8(b) and 8(c). Among the three kinds of carbon black, only bpc40 and bpc20 could self-assemble together with dispersions of polymer/silica and form periodic arrays.

\subsection{The Effect of Temperature on Film Forming Rates and Prop-} erties of Polymer Films. The film forming rate $(v)$ increased from $1.70 \mathrm{~g} / \mathrm{s}$ to $2.24 \mathrm{~g} / \mathrm{s}$ when the temperature increased from $20^{\circ} \mathrm{C}$ to $40^{\circ} \mathrm{C}$ as shown in Figure 9(a). It is known that water evaporation rate increases with the increasing evaporation temperature. So the higher the temperature, the faster the film forming rate.

Figure $9(\mathrm{~b})$ is the reflection spectra of CCB film assembled at $20^{\circ} \mathrm{C}, 25^{\circ} \mathrm{C}, 30^{\circ} \mathrm{C}$, and $40^{\circ} \mathrm{C}$, respectively. The peak positions blue-shifted with the increasing temperature. According to Bragg's law, the peak position $\lambda=$ $2 n d_{0} \sqrt{1-\sin ^{2} \theta / n^{2}}$ had the relationship with the effective reflective index $n$ and the distance $d_{0}$ between [111] planes. For CCB films made under different temperatures with other invariant conditions, the effective reflective index $n$ remained unchanged. The [111] plane spacing $d_{0}$ can be calculated by $d_{0}=\sqrt{2 / 3} D$, where $D$ is the diameter of polymer spheres. When the temperature was $20^{\circ} \mathrm{C}$, lower than the $T_{g}$ of the polymer spheres, the polymer spheres in the crystal film remained in spherical shapes as shown in Figure 10(a). So [111] plane distance $d_{0}$ could be calculated by $d_{0}=\sqrt{2 / 3} \mathrm{D}$. When the temperature increased to $25^{\circ} \mathrm{C}$ and $30^{\circ} \mathrm{C}$, higher than the $T_{g}$ of the polymer spheres, the soft polymer spheres began to coalesce and fuse slightly as shown in Figures 10(b) and $10(\mathrm{c})$. The polymer spheres along [111] collapsed and became flatter, which led to [111] plane spacing being smaller than $d_{0}$. When the temperature further increased to $40^{\circ} \mathrm{C}$, the polymer spheres further coalesced and fused as shown Figure 10(d), which caused flatter polymer spheres along [111] plane and smaller [111] plane spacing than at $30^{\circ} \mathrm{C}$. This decreasing [111] plane spacing caused blue shifts in reflection spectra as demonstrated in Figure 9(b).

The temperature also has effects on the peak height of the spectra. Figure 9(b) demonstrates that the peak height increases from $9 \%$ to $19 \%$ when the temperature increases from $20^{\circ} \mathrm{C}$ to $30^{\circ} \mathrm{C}$ and decreases to $5 \%$ when the temperature further increases to $40^{\circ} \mathrm{C}$. Figure 11 (a) shows that when the temperature is $20^{\circ} \mathrm{C}$, the stress resulted from water evaporation produces cracks and the formed film is crisp. The quality of the film is poor and the peak height is low. When the temperature increases to $25^{\circ} \mathrm{C}$, even to $30^{\circ} \mathrm{C}$, higher than $T_{g}$, domain size increases and the cracks diminish as shown in Figures 11(b) and 11(c). Only small fissures exist in CCB films. So the peak height is higher than that at $20^{\circ} \mathrm{C}$. When the temperature further increases to $40^{\circ} \mathrm{C}$, Figure $11(\mathrm{~d})$ shows that, though no cracks exist in the films, the fissures 


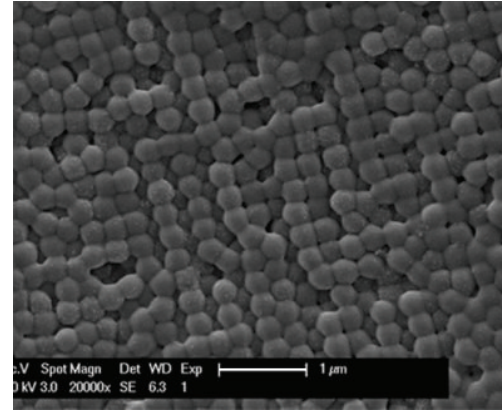

(a)

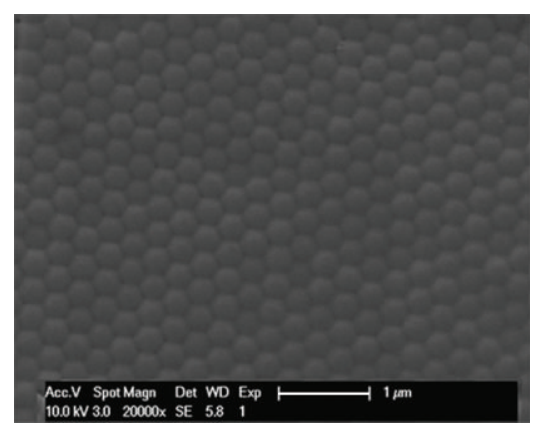

(b)

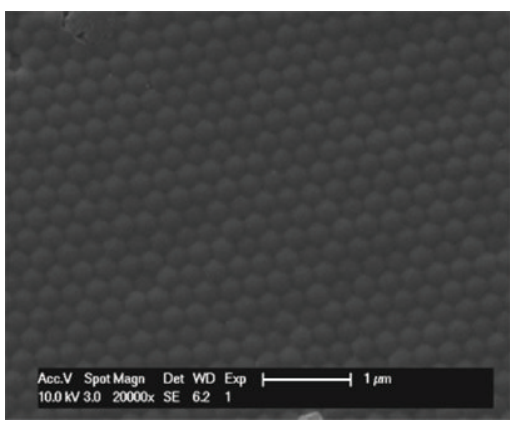

(c)

FIGURE 8: SEM images of crystal films with carbon black vxc72 in (a), bpc40 in (b), and bpc20 in (c).

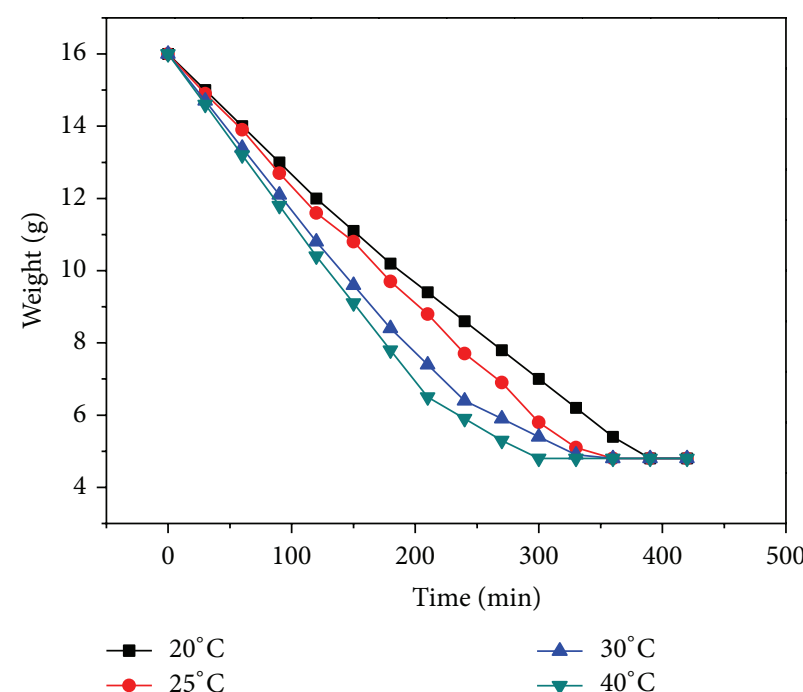

(a)

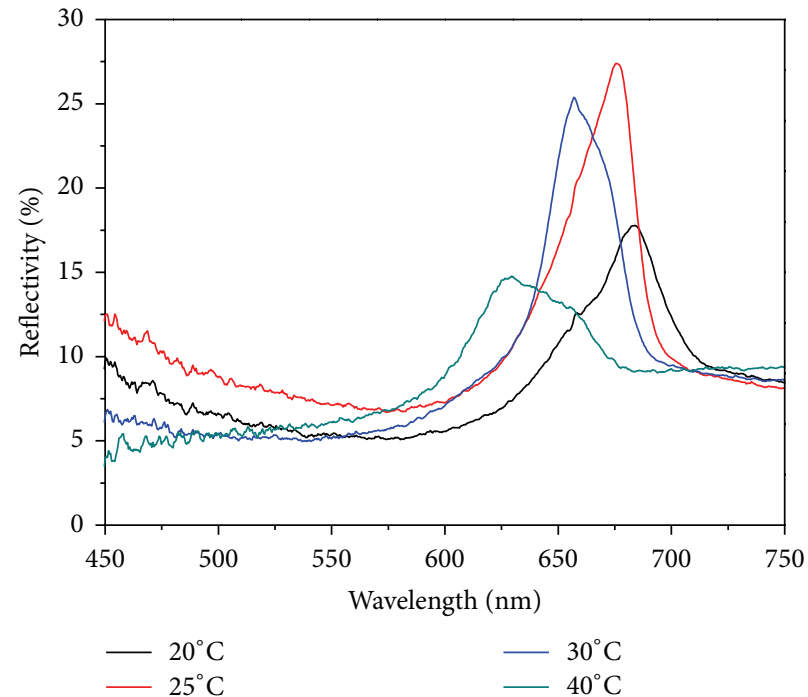

(b)

FIGURE 9: Film forming rates in (a) and reflection spectra in (b) at different temperatures.

and the domain density in CCB films increase. So the peak height decreases. Figures $11(\mathrm{f})$ and $11(\mathrm{~g})$ show that the chroma factors of the films at $25^{\circ} \mathrm{C}$ and $30^{\circ} \mathrm{C}$ are 10.37 and 12.16 , higher than 4.05 and 6.76 at $20^{\circ} \mathrm{C}$ and $40^{\circ} \mathrm{C}$ as shown in Figures $11(\mathrm{e})$ and $11(\mathrm{~h})$. Therefore the temperature has great effects on microstructures and optical properties of the films. The appropriate temperatures are $25^{\circ} \mathrm{C}$ and $30^{\circ} \mathrm{C}$.

\subsection{The Effect of RH on Film Forming Rates and Properties} of Polymer Film. Figure 12(a) shows that the film forming rate decreases from $2.49 \mathrm{~g} / \mathrm{s}$ to $1.72 \mathrm{~g} / \mathrm{s}$ when $\mathrm{RH}$ increases from $50 \%$ to $80 \%$. According to $(3)[27,33]$, where $D$ is the diffusion coefficient of water vapor in air; $L$ is the distance from the liquid surface to the open end of the vial; $R_{0}$ is the gas constant of water vapor; $T$ is the boiling temperature of solvent, and $P, P_{0}$, and $P_{w}$ are the total pressures in the growth conditioner, the vapor pressure at the open end of the vial, and at the liquid surface, respectively, the film forming rate $v$ has relationships with $P_{0}$ when other factors are invariant. RH could be calculated by RH $=P_{0} / P$. The higher the
$P_{0}$, the higher the RH and the lower the film forming rate is

$$
v=\frac{\mathrm{DP}}{\mathrm{LTR}_{0}} \ln \left[\frac{\left(P-P_{0}\right)}{\left(P-P_{w}\right)}\right] .
$$

Figure 12(b) demonstrates that the peak position blueshifts $60 \mathrm{~nm}$ when RH increases from $50 \%$ to $80 \%$. According to Bragg's diffraction law, the peak positions have relationship with the distance $d_{0}$ between [111] planes with other invariant factors. Figure 13 shows that the higher the $\mathrm{RH}$, the flatter the polymer spheres along [111] planes and the smaller the [111] plane distance $d_{0}$. The soft polymer spheres deform least and keep in good spherical shape when RH is $50 \%$ as shown in Figure 13(a). The polymers deform most and become flattest along [111] plane when RH is $80 \%$ as shown in Figure 13(d). It is just the deformation of polymer spheres that leads to the reduction in [111] plane distances and therefore the blue shifts in the peak positions.

The optical images in Figures 14(a), 14(b), and 14(c) show that, when RH increases from $50 \%, 60 \%$ to $70 \%$, the 


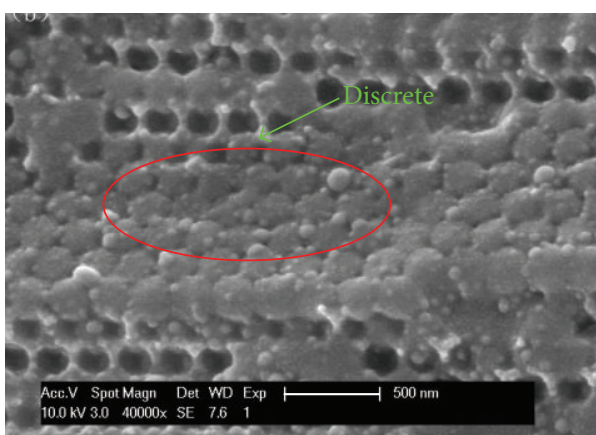

(a)

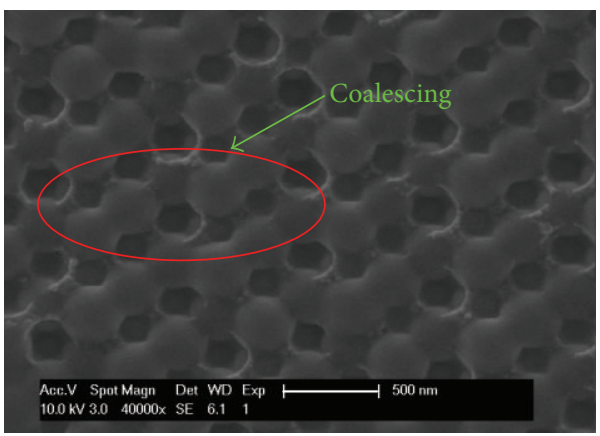

(c)

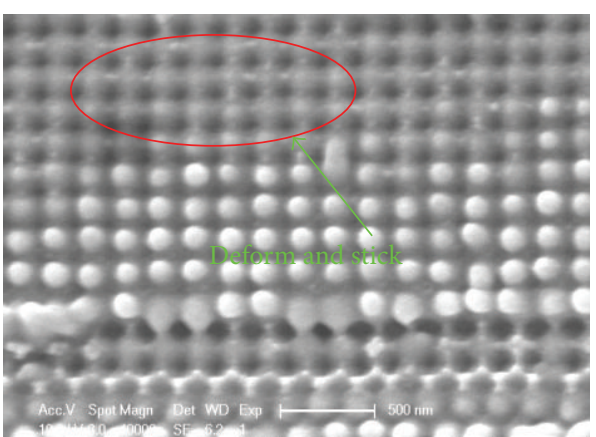

(b)

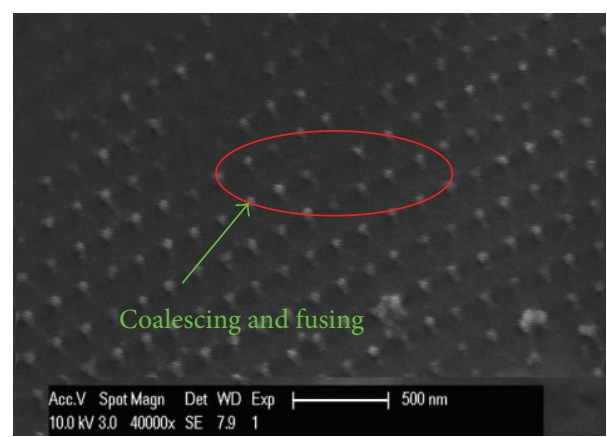

(d)

Figure 10: Cross-sectional SEM images of CCB film assembled at (a) $20^{\circ} \mathrm{C}$, (b) $25^{\circ} \mathrm{C}$, (c) $30^{\circ} \mathrm{C}$, and (d) $40^{\circ} \mathrm{C}$.

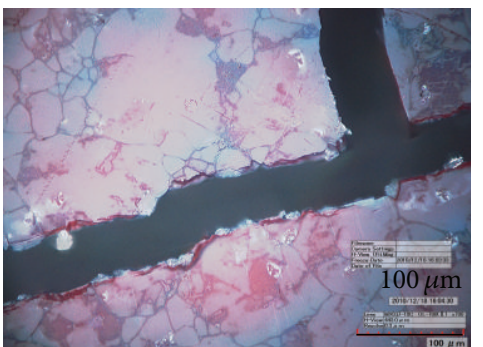

(a)

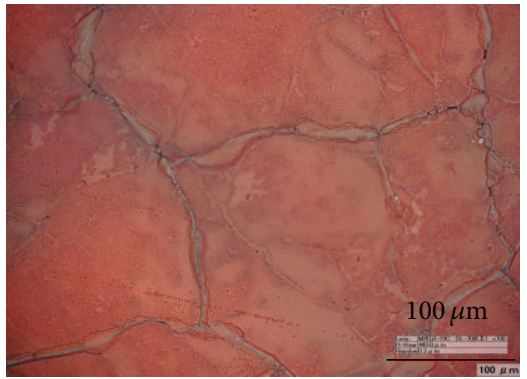

(d)

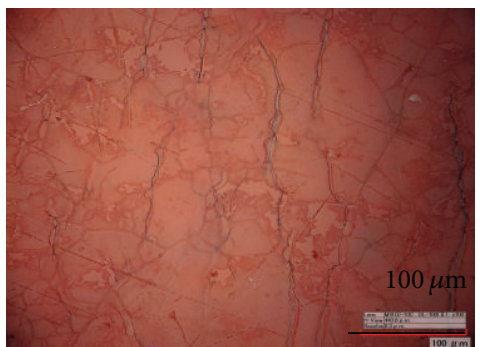

(b)

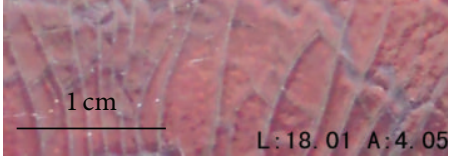

(e)

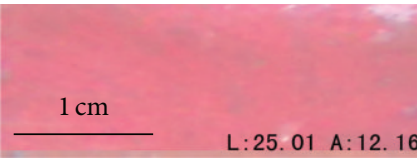

(f)

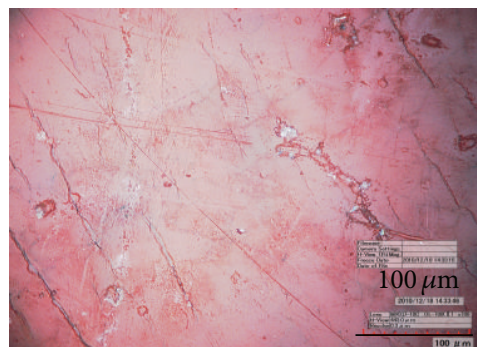

(c)

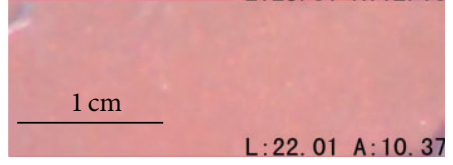

(g)

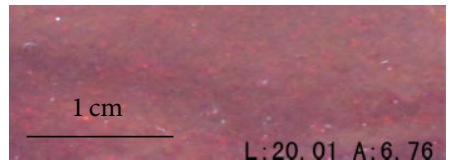

(h)

Figure 11: Optical images of CCB film assembled at (a) $20^{\circ} \mathrm{C}$, (b) $25^{\circ} \mathrm{C}$, (c) $30^{\circ} \mathrm{C}$, and (d) $40^{\circ} \mathrm{C}$; digital pictures of the films assembled at (e) $20^{\circ} \mathrm{C}$, (f) $25^{\circ} \mathrm{C}$, (g) $30^{\circ} \mathrm{C}$, and (h) $40^{\circ} \mathrm{C}$.

domain density and fissures decrease. So the films assembled at $60 \%$ and $70 \% \mathrm{RH}$ have better quality than at $50 \% \mathrm{RH}$. The peak height increases. When $\mathrm{RH}$ is $80 \%$, the fissures reduce while the domain density increases as shown in Figure 14(d). The peak height decreases. During self-assembly of the dispersions of polymer/silica/carbon black, the liquid phase forms capillary bridges between particles, and capillary force is produced by the capillary bridges. So the dispersions selfassemble into orderly structures driven by the comprehensive force of static repulsive force, van der Waals force and 


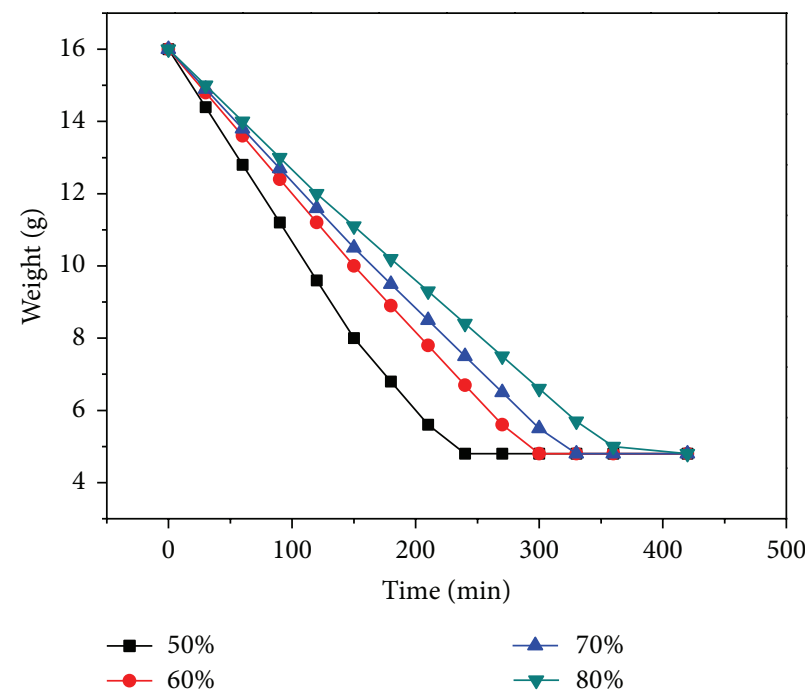

(a)

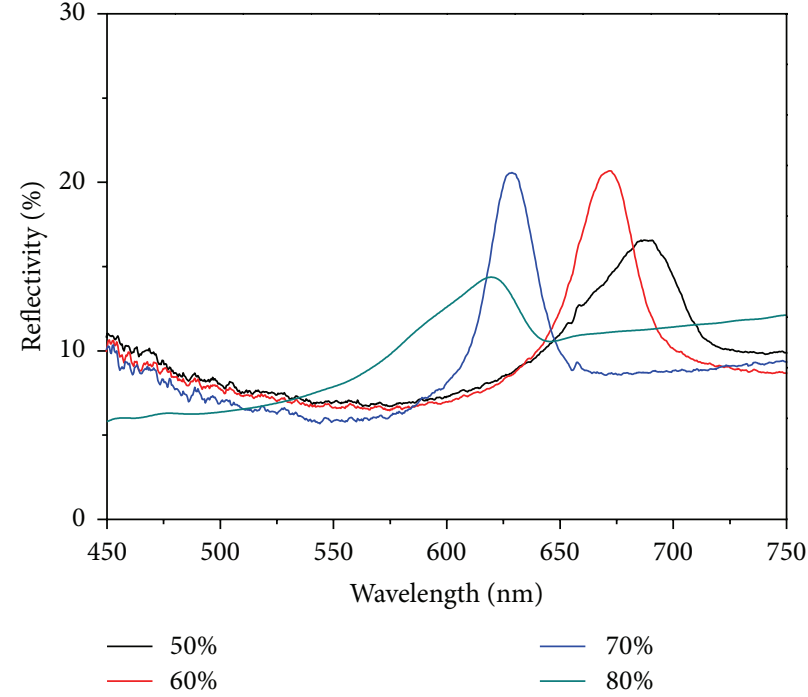

(b)

FigURE 12: Film forming rates in (a) and reflection spectra in (b) at different RH.

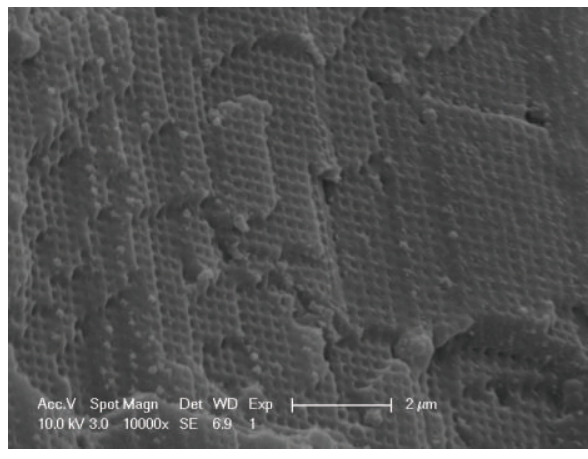

(a)

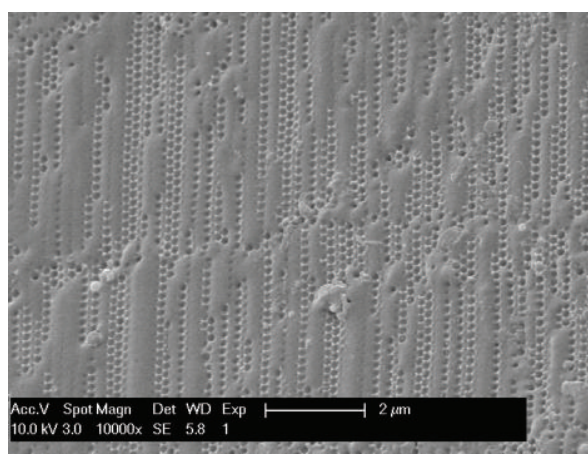

(c)

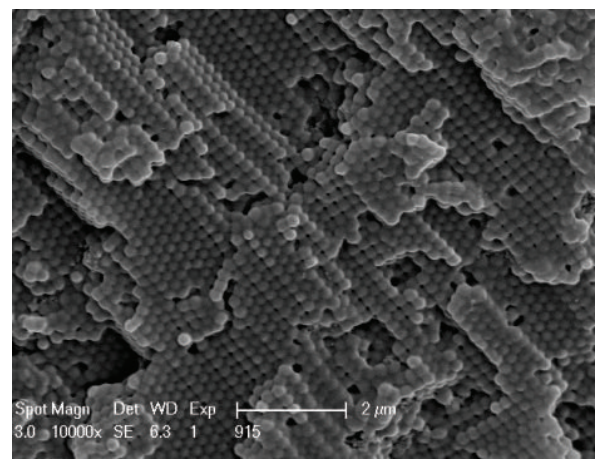

(b)

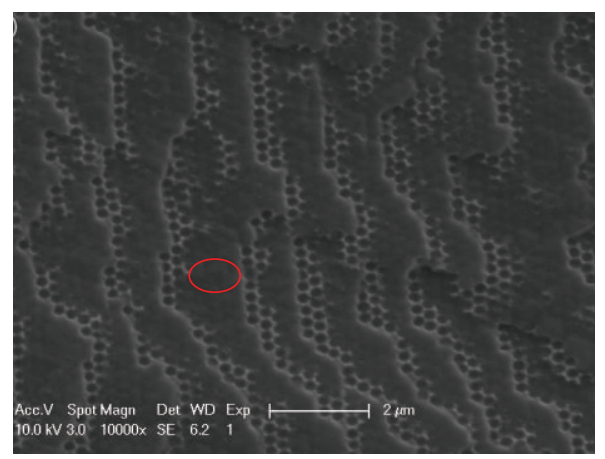

(d)

Figure 13: SEM images of CCB films assembled at RH (a) 50\%, (b) 60\%, (c) 70\%, and (d) $80 \%$.

capillary force [34]. A lower RH corresponds to a larger lateral capillary force, and the result is the presence of smaller domains in the colloidal crystals. A lower RH also promotes higher array growth rate so as to bring the additional internal stress, which explains the splits and defects in CCB films shown in Figure 14(a). With increasing RH, on the other hand, the lateral capillary force is lower and the array growth rate will decrease, which results in a better crystalline quality and a higher peak height as shown in Figure 14(b). But when $\mathrm{RH}$ is $80 \%$, too high $\mathrm{RH}$ leads to too slow array growth rate and too weak lateral force, and then the colloidal crystal with poor quality is formed [33]. So for ternary dispersions, the 


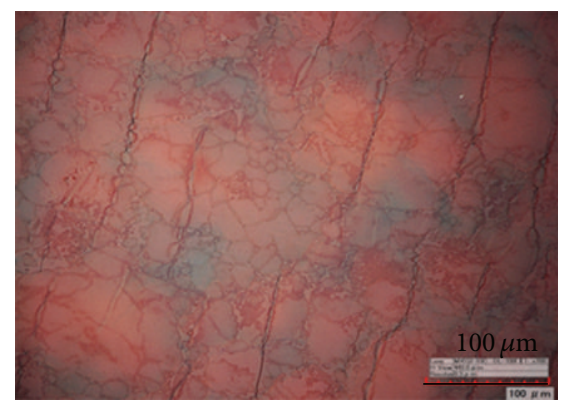

(a)

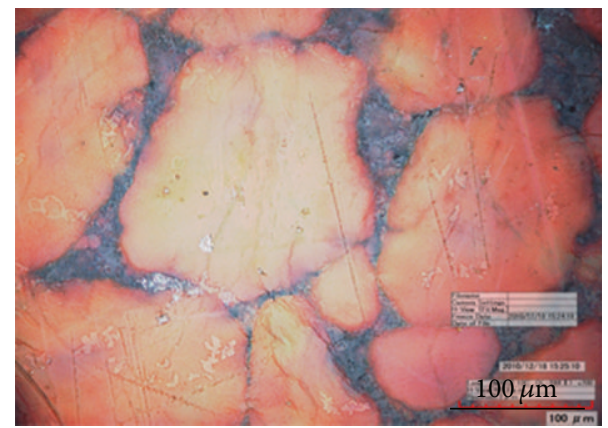

(d)

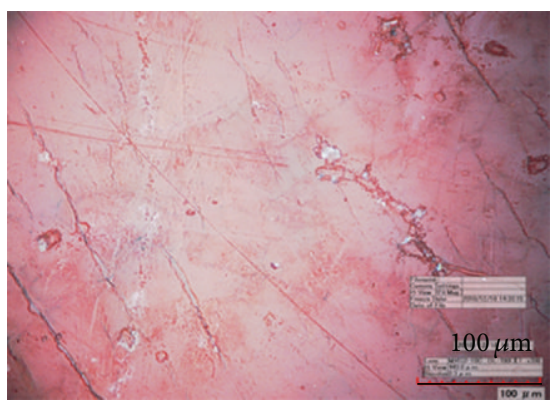

(b)

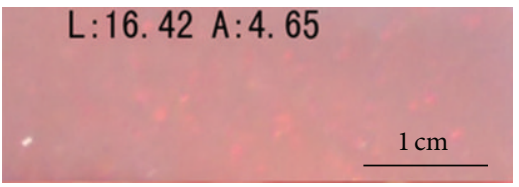

(e)

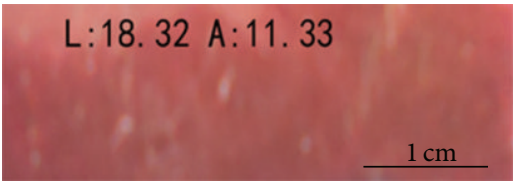

(f)

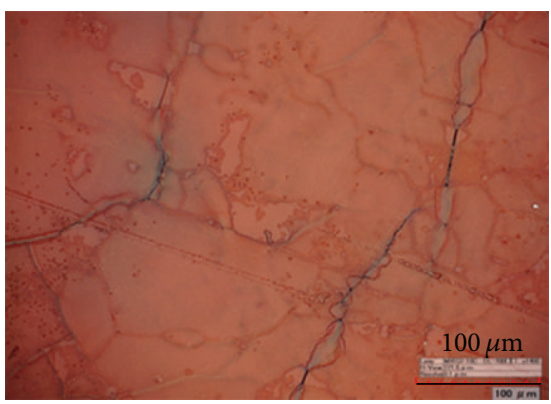

(c)

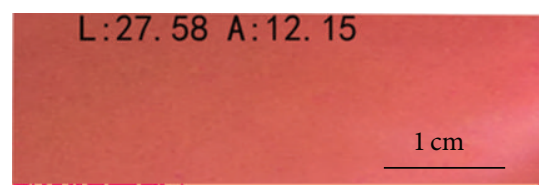

(g)

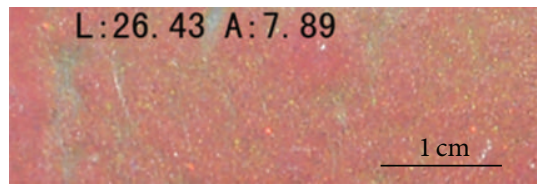

(h)

FIGURE 14: Optical images of CCB films assembled at RH (a) 50\%, (b) 60\%, (c) 70\%, and (d) $80 \%$ and digital pictures of CCB films at RH (e) $50 \%$, (f) $60 \%$, (g) $70 \%$, and (h) $80 \%$.

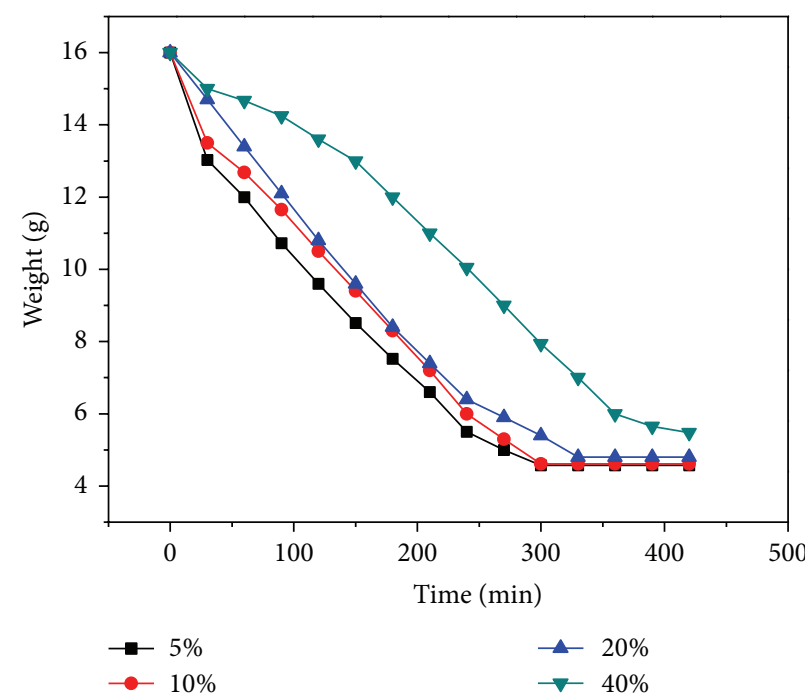

(a)

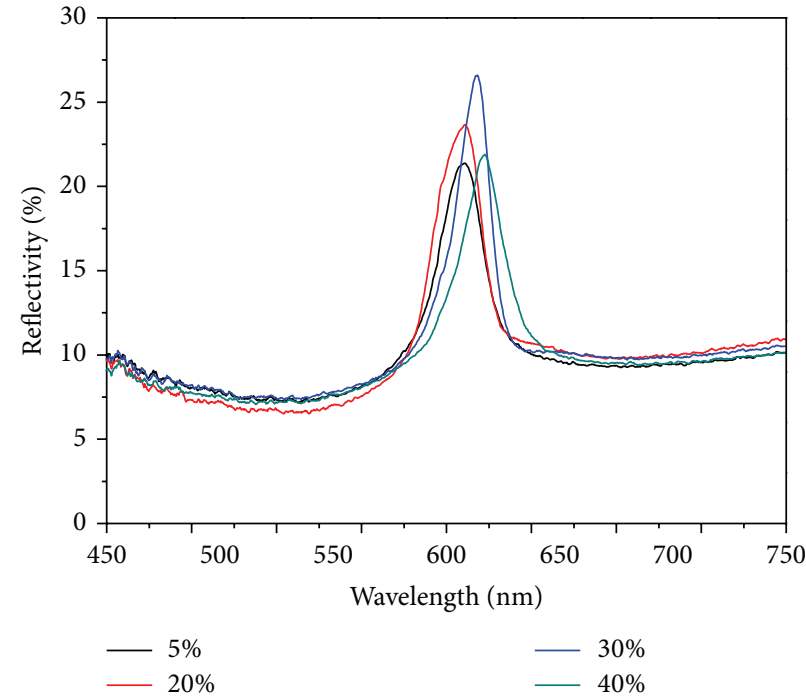

(b)

FIGURE 15: Film forming rates in (a) and reflection spectra in (b) at different silica contents.

appropriate $\mathrm{RH}$ is $60 \%$ and $70 \%$. Figures $14(\mathrm{f})$ and $14(\mathrm{~g})$ show that the chroma factors of CCB films at $60 \%$ and $70 \%$ are 12.15 and 11.33 , higher than 4.65 and 7.89 at $50 \%$ and $80 \%$ as shown in Figures 14(e) and 14(h). This means that CCB films at $60 \%$ and $70 \% \mathrm{RH}$ are purer than at $50 \%$ and $80 \% \mathrm{RH}$.

3.6. The Effect of Silica Content on Film Forming Rates and Properties of Polymer Film. Figure 15(a) shows that, with the increase in silica content from $5 \%$ to $40 \%$, the film forming rate decreases from $2.29 \mathrm{~g} / \mathrm{s}$ to $1.50 \mathrm{~g} / \mathrm{s}$. The reason is that the water evaporates slowly because the increased dispersion viscosity resulted by increasing silica content prevents water from flowing freely and quickly. Figure 15(b) is the reflection spectra of CCB films with different silica contents. When silica content increases from $5 \%$ to $20 \%$, the peak heights increase from 9 to $17 \%$. When silica content further increases 


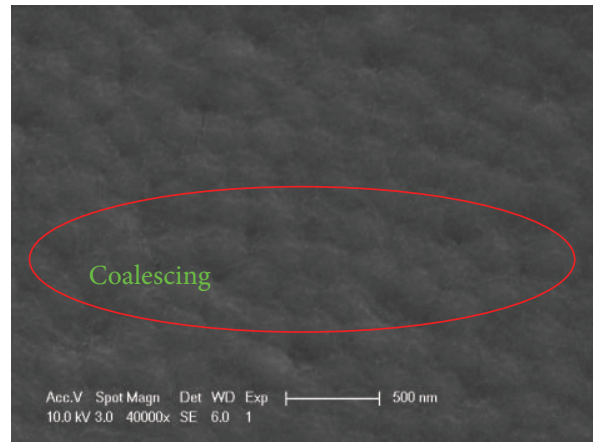

(a)

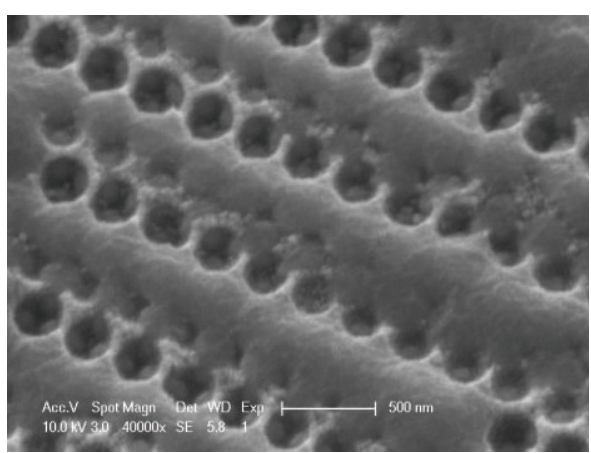

(c)

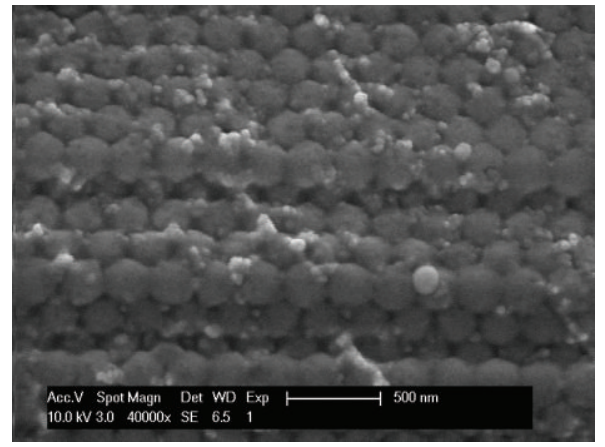

(b)

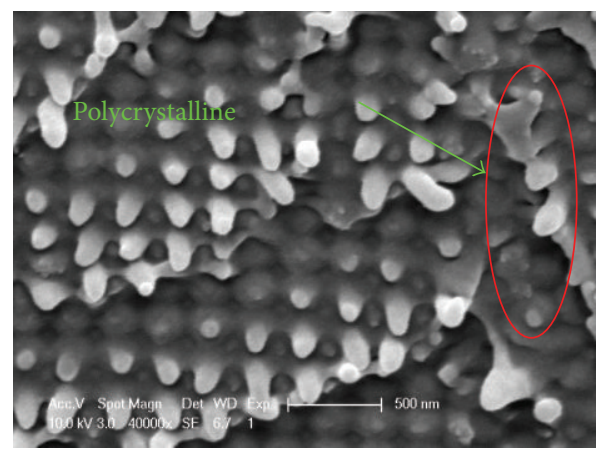

(d)

Figure 16: SEM images of CCB film assembled with silica content (a) 5\%, (b) 20\%, (c) 30\%, and (d) $40 \%$.

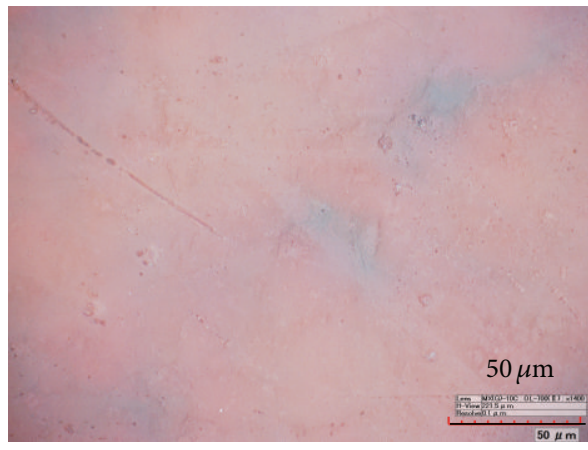

(a)

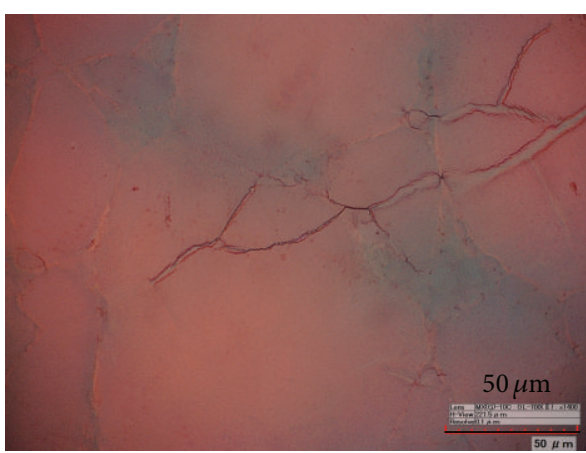

(c)

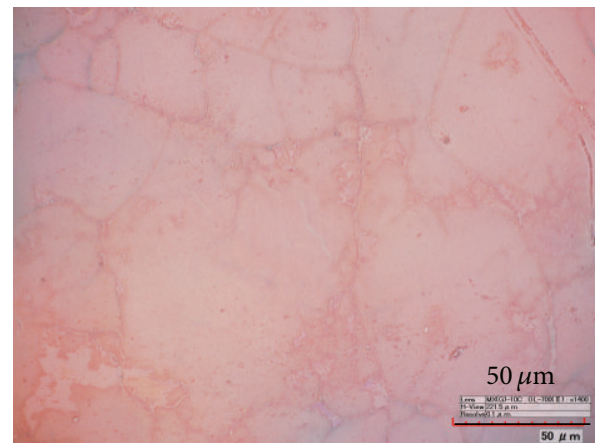

(b)

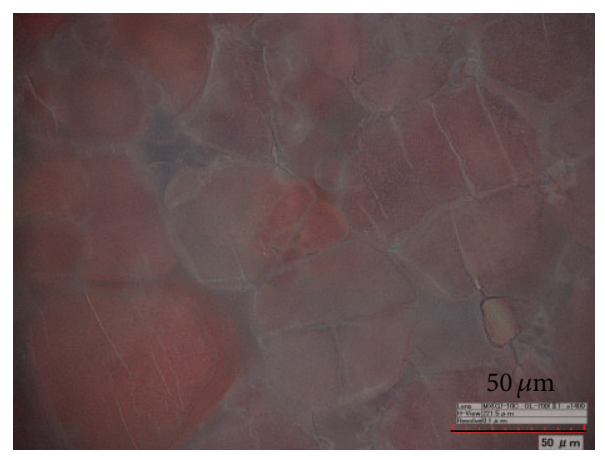

(d)

FIGURE 17: Optical images of CCB film assembled with silica content (a) 5\%, (b) 10\%, (c) 20\%, and (d) $40 \%$. 


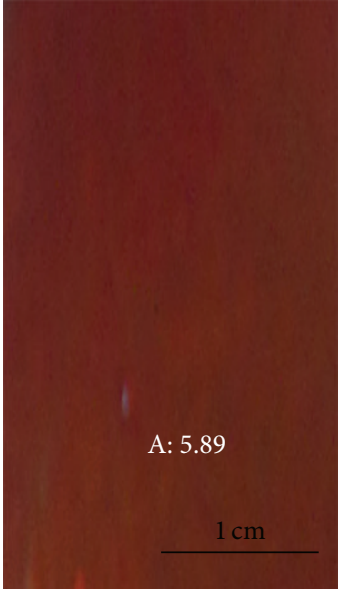

(a)

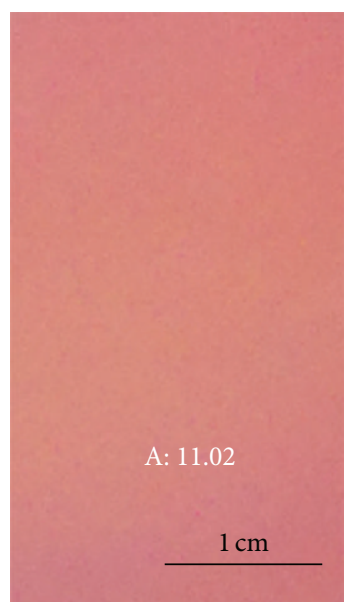

(b)

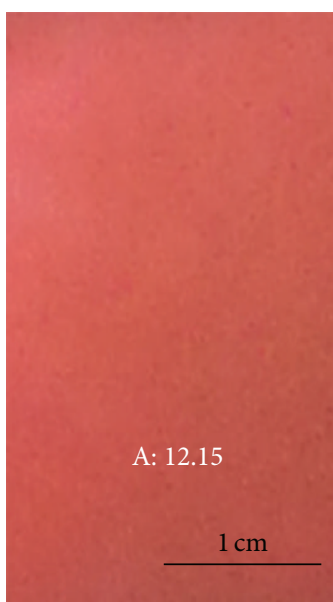

(c)

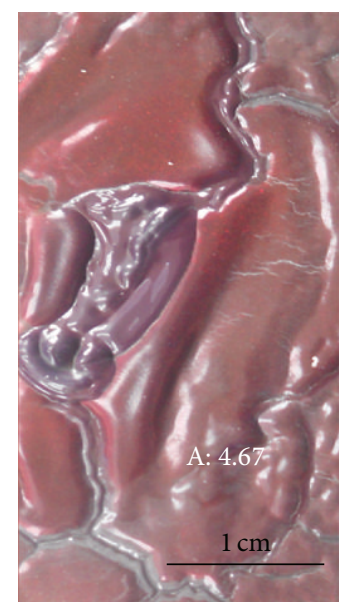

(d)

Figure 18: Digital pictures of CCB films with silica content (a) 5\%, (b) $10 \%$, (c) 20\%, and (d) $40 \%$.

to $40 \%$, the peak height reduces to $10 \%$. The peak height reaches its maximum when $20 \mathrm{wt} \%$ of silica is used.

When $5 \mathrm{wt} \%$ of silica is used, silica and carbon black particles are not enough to locate around the polymer or in the interstices to prevent polymer spheres from coalescing or fusing. The polymer spheres coalesce and fuse so severely that boundary lines between two dielectric constants are not clear, which could not prevent the dislocation or vacancy or fusing of the polymer spheres in the periodic arrays as shown in Figure 16(a). Optical images in Figure 17(a) show no domains or splits, which on the other hand proves the nearly homogeneous surface of CCB films. So the peak height is low. When silica content is $10 \%$ and $20 \%$, silica or carbon particles is enough to locate around the polymer spheres to prevent them from coalescing or fusing as shown in Figures 16(b) and $16(\mathrm{c})$; thus, the peak height increases correspondingly. When silica content is $40 \%$, the viscosity of the dispersions increases so much that air and water could not completely evaporate from the dispersions. The convective flux could not bring the spheres or particles into already ordered arrays for crystal growth timely, which leads to polycrystalline regions as shown in Figure 16(d) or increases the domain density and corrugations as shown in Figure 17(d). Digital pictures in Figures 18(b) and 18(c) show that the chrome factors of polymer films with $10 \%$ and $20 \%$ silica content are 11.02 and 12.15, higher than 5.89 and 4.67 for the films with $5 \%$ and $40 \%$ silica content as shown in Figures 18(a) and 18(d). For the dispersions of polymer/silica/carbon black, the optimal silica content is $10 \%$ and $20 \%$.

\subsection{The Relationships between Peak Height and Film Forming}

Rates. Figure 19 shows that the film forming rates have great effects on the peak height under different conditions. When the rates range from $1.87 \mathrm{~g} / \mathrm{s}$ to $2.03 \mathrm{~g} / \mathrm{s}$, the peak height is more than $10 \%$. When film forming rate is less than $1.70 \mathrm{~g} / \mathrm{s}$ or more than $2.03 \mathrm{~g} / \mathrm{s}$, the peak heights begin to reduce. The
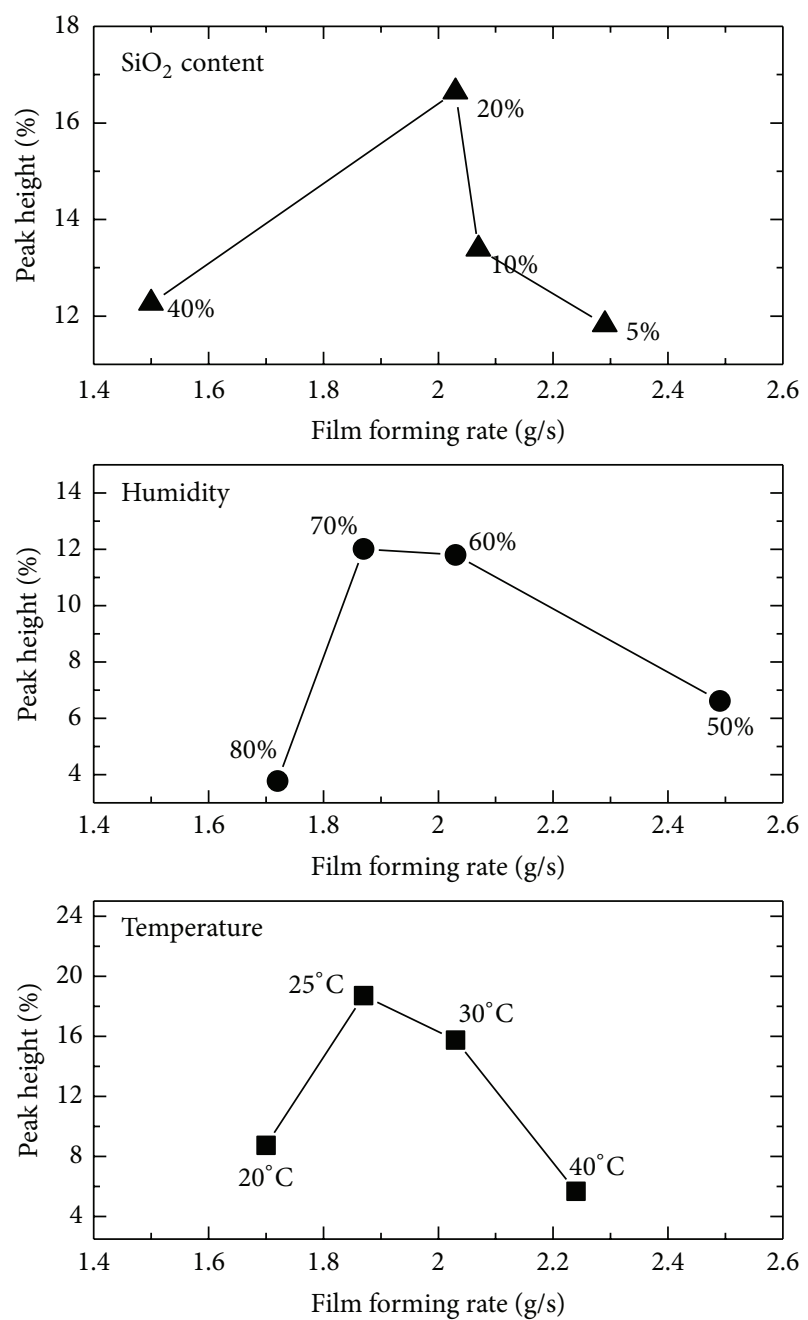

FIGURE 19: The relationship between peak height and film forming rate under different factors. 
formations of layered arrays from polymer, silica, and carbon black could be split into two stages: (1) convective transfer of particles from the bulk suspension to the thin wetting film and (2) interactions between particles that lead to specific textures. If these two stages nearly balance, the high quality of ordered arrays could be formed [35]. When the film forming rate is less than $1.70 \mathrm{~g} / \mathrm{s}$ or more than $2.03 \mathrm{~g} / \mathrm{s}$, the convective transfer of particle is so low or fast that it could not match the assembly process and therefore forms the crystalline array of low quality. So for colloidal particles of soft polymer, silica and carbon black, to get high crystalline quality, the film forming rate is better to be controlled between $1.87 \mathrm{~g} / \mathrm{s}$ and $2.03 \mathrm{~g} / \mathrm{s}$ under whatever factor.

\section{Conclusion}

Based on this study, large-scale, robust, intense, and structurally color-tunable polymer crystal films can be successfully fabricated by casting method. This method is not only simple and feasible, but the as-obtained polymer crystal films also display brilliant visual iridescence under natural lighting conditions. Under the optimal conditions, the obtained CCB has the best quality with suitable film forming rate, which provides basis for the mass production and application of the colloidal crystal films with carbon black dopant in coating, cosmetics, and pigments.

\section{Conflict of Interests}

None of the authors of this paper has any direct financial relation with the commercial identities mentioned in the paper that might lead to a conflict of interests.

\section{Acknowledgments}

Financial supports of this research from the NSF (no. 30700628), Zhejiang Innovative Group (2010R50023), and Talents Foundation from Zhejiang Agriculture and Forestry University (2011FR041) are appreciated.

\section{References}

[1] X. Zhao, Y. Cao, F. Ito et al., "Colloidal crystal beads as supports for biomolecular screening," Angewandte Chemie, vol. 45, no. 41, pp. 6835-6838, 2006.

[2] H. Fudouzi and Y. Xia, "Colloidal crystals with tunable colors and their use as photonic papers," Langmuir, vol. 19, no. 23, pp. 9653-9660, 2003.

[3] J. R. Lawrence, Y. Ying, P. Jiang, and S. H. Foulger, "Dynamic tuning of organic lasers with colloidal crystals," Advanced Materials, vol. 18, no. 3, pp. 300-303, 2006.

[4] O. D. Velev and A. M. Lenhoff, "Colloidal crystals as templates for porous materials," Current Opinion in Colloid and Interface Science, vol. 5, no. 1-2, pp. 56-63, 2000.

[5] J. R. Lawrence, G. H. Shim, P. Jiang, M. G. Han, Y. Ying, and S. H. Foulger, "Dynamic tuning of photoluminescent dyes in crystalline colloidal arrays," Advanced Materials, vol. 17, no. 19, pp. 2344-2349, 2005.
[6] H. Takei and N. Shimizu, "Gradient sensitive microscopic probes prepared by gold evaporation and chemisorption on latex spheres," Langmuir, vol. 13, no. 7, pp. 1865-1868, 1997.

[7] J. Ge and Y. Yin, "Magnetically responsive colloidal photonic crystals," Journal of Materials Chemistry, vol. 18, no. 42, pp. 5041-5045, 2008.

[8] M. Mitsuishi, J. Matsui, and T. Miyashita, "Photofunctional thin film devices composed of polymer nanosheet assemblies," Journal of Materials Chemistry, vol. 19, no. 3, pp. 325-329, 2009.

[9] S. A. Asher, V. L. Alexeev, A. V. Goponenko et al., "Photonic crystal carbohydrate sensors: low ionic strength sugar sensing," Journal of the American Chemical Society, vol. 125, no. 11, pp. 3322-3329, 2003.

[10] Y. Zhang, J. Wang, Y. Zhao et al., "Photonic crystal concentrator for efficient output of dye-sensitized solar cells," Journal of Materials Chemistry, vol. 18, no. 23, pp. 2650-2652, 2008.

[11] H. Fudouzi and Y. Xia, "Photonic papers and inks: color writing with colorless materials," Advanced Materials, vol. 15, no. 11, pp. 892-896, 2003.

[12] J. H. Holtz and S. A. Asher, "Polymerized colloidal crystal hydrogel films as intelligent chemical sensing materials," Nature, vol. 389, no. 6653, pp. 829-832, 1997.

[13] M. Li, F. He, Q. Liao et al., "Ultrasensitive DNA detection using photonic crystals," Angewandte Chemie, vol. 120, no. 38, pp. 7368-7372, 2008.

[14] P. Vukusic and J. R. Sambles, "Photonic structures in biology," Nature, vol. 424, no. 6950, pp. 852-855, 2003.

[15] Y. Li, W. P. Cai, and G. T. Duan, "Ordered micro/nanostructured arrays based on the monolayer colloidal crystals," Chemistry of Materials, vol. 20, no. 3, pp. 615-624, 2008.

[16] F. Marlow, Muldarisnur, P. Sharifi, R. Brinkmann, and C. Mendive, "Opals: status and prospects," Angewandte Chemie, vol. 48, no. 34, pp. 6212-6233, 2009.

[17] Y. Li, T. Sasaki, Y. Shimizu, and N. Koshizaki, "Hexagonal-closepacked, hierarchical amorphous $\mathrm{TiO}_{2}$ nanocolumn arrays: transferability, enhanced photocatalytic activity, and superamphiphilicity without UV irradiation," Journal of the American Chemical Society, vol. 130, no. 44, pp. 14755-14762, 2008.

[18] Y. Lu, Y. D. Yin, Z.-Y. Li, and Y. N. Xia, "Synthesis and selfassembly of $\mathrm{Au} @ \mathrm{SiO}_{2}$ core shell colloids," Nano Letters, vol. 2, no. 7, pp. 785-788, 2002.

[19] M. Mitsuishi, J. Matsui, and T. Miyashita, "Photofunctional thin film devices composed of polymer nanosheet assemblies," Journal of Materials Chemistry, vol. 19, no. 3, pp. 325-329, 2009.

[20] Y. N. Xia, B. Gates, Y. D. Yin, and Y. Lu, "Monodispersed colloidal spheres: old materials with new applications," Advanced Materials, vol.12, no. 10, pp. 693-713, 2000.

[21] A. C. Arsenault, D. P. Puzzo, I. Manners, and G. A. Ozin, "Photonic-crystal full-colour displays," Nature Photonics, vol. 1, no. 8, pp. 468-472, 2007.

[22] L. L. Duan, B. You, S. X. Zhou, and L. M. Wu, "Self-assembly of polymer colloids and their solvatochromic-responsive properties," Journal of Materials Chemistry, vol. 21, no. 3, pp. 687-692, 2011.

[23] Z. H. Shen, Y. Zhu, L. M. Wu, B. You, and J. Zi, "Fabrication of robust crystal balls from the electrospray of soft polymer spheres/silica dispersion," Langmuir, vol. 26, no. 9, pp. 66046609, 2010.

[24] B. You, L. Shi, N. G. Wen et al., "A facile method for fabrication of ordered porous polymer films," Macromolecules, vol. 41, no. 18, pp. 6624-6626, 2008. 
[25] J. H. Moon and S. Yang, "Chemical aspects of three-dimensional photonic crystals," Chemical Reviews, vol. 110, no. 1, pp. 547-574, 2010.

[26] Z. H. Shen, Y. Y. Yang, F. Z. Lu, B. F. Bao, and B. You, "Self-assembly of binary particles and application as structural colors," Polymer Chemistry, vol. 3, no. 9, pp. 2495-2501, 2012.

[27] X. H. Wang, T. Akahane, H. Orikasa, T. Kyotani, and Y. Y. $\mathrm{Fu}$, "Brilliant and tunable color of carbon-coated thin anodic aluminum oxide films," Applied Physics Letters, vol. 91, no. 1, Article ID 011908, 3 pages, 2007.

[28] O. L. J. Pursiainen, J. J. Baumberg, H. Winkler, B. Viel, P. Spahn, and T. Ruhl, "Nanoparticle-tuned structural color from polymer opals," Optics Express, vol. 15, no. 15, pp. 9553-9561, 2007.

[29] J. Zi, X. D. Yu, Y. Z. Li et al., "Coloration strategies in peacock feathers," Proceedings of the National Academy of Sciences of the United States of America, vol. 100, no. 22, pp. 12576-12578, 2003.

[30] Z. H. Shen, L. Shi, B. You, L. M. Wu, and D. Y. Zhao, "Largescale fabrication of three-dimensional ordered polymer films with strong structure colors and robust mechanical properties," Journal of Materials Chemistry, vol. 22, no. 16, pp. 8069-8075, 2012.

[31] X. D. Yu, Y. J. Lee, R. Furstenberg, J. O. White, and P. V. Braun, "Filling fraction dependent properties of inverse opal metallic photonic crystals," Advanced Materials, vol. 19, no. 13, pp. 1689$1692,2007$.

[32] N. Stefanou, V. Yannopapas, and A. Modinos, "Heterostructures of photonic crystals: frequency bands and transmission coefficients," Computer Physics Communications, vol. 113, no. 1, pp. 49-77, 1998.

[33] G. Q. Liu, Z. S. Wang, and Y. H. Ji, "Influence of growth parameters on the fabrication of high-quality colloidal crystals via a controlled evaporation self-assembly method," Thin Solid Films, vol. 518, no. 18, pp. 5083-5090, 2010.

[34] P. A. Kralchevsky and N. D. Denkov, "Capillary forces and structuring in layers of colloid particles," Current Opinion in Colloid \& Interface Science, vol. 6, no. 4, pp. 383-401, 2001.

[35] S.-L. Kuai, X.-F. Hu, A. Haché, and V.-V. Truong, "High-quality colloidal photonic crystals obtained by optimizing growth parameters in a vertical deposition technique," Journal of Crystal Growth, vol. 267, no. 1-2, pp. 317-324, 2004. 

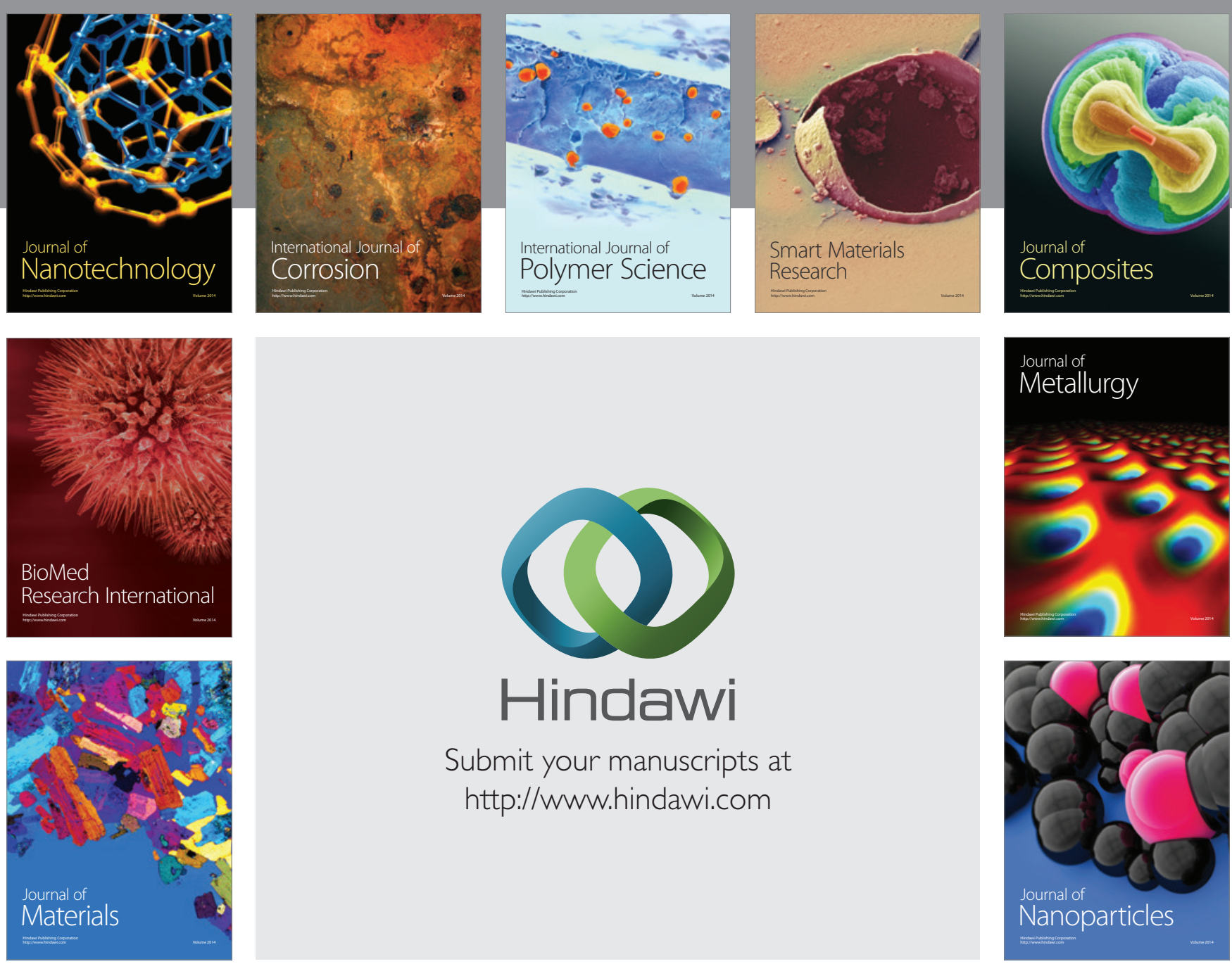

Submit your manuscripts at http://www.hindawi.com
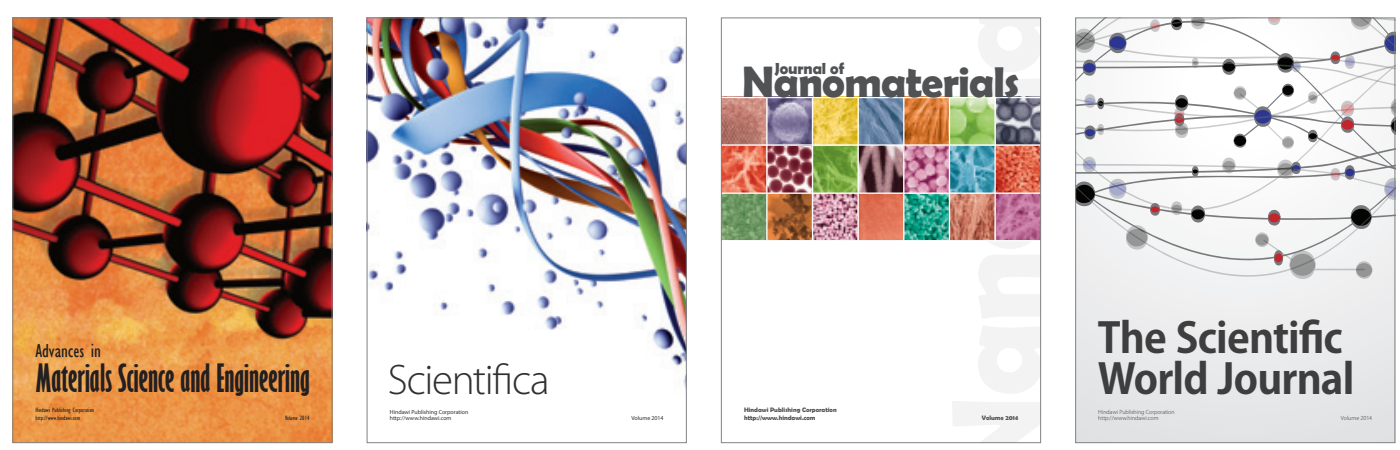

\section{The Scientific World Journal}
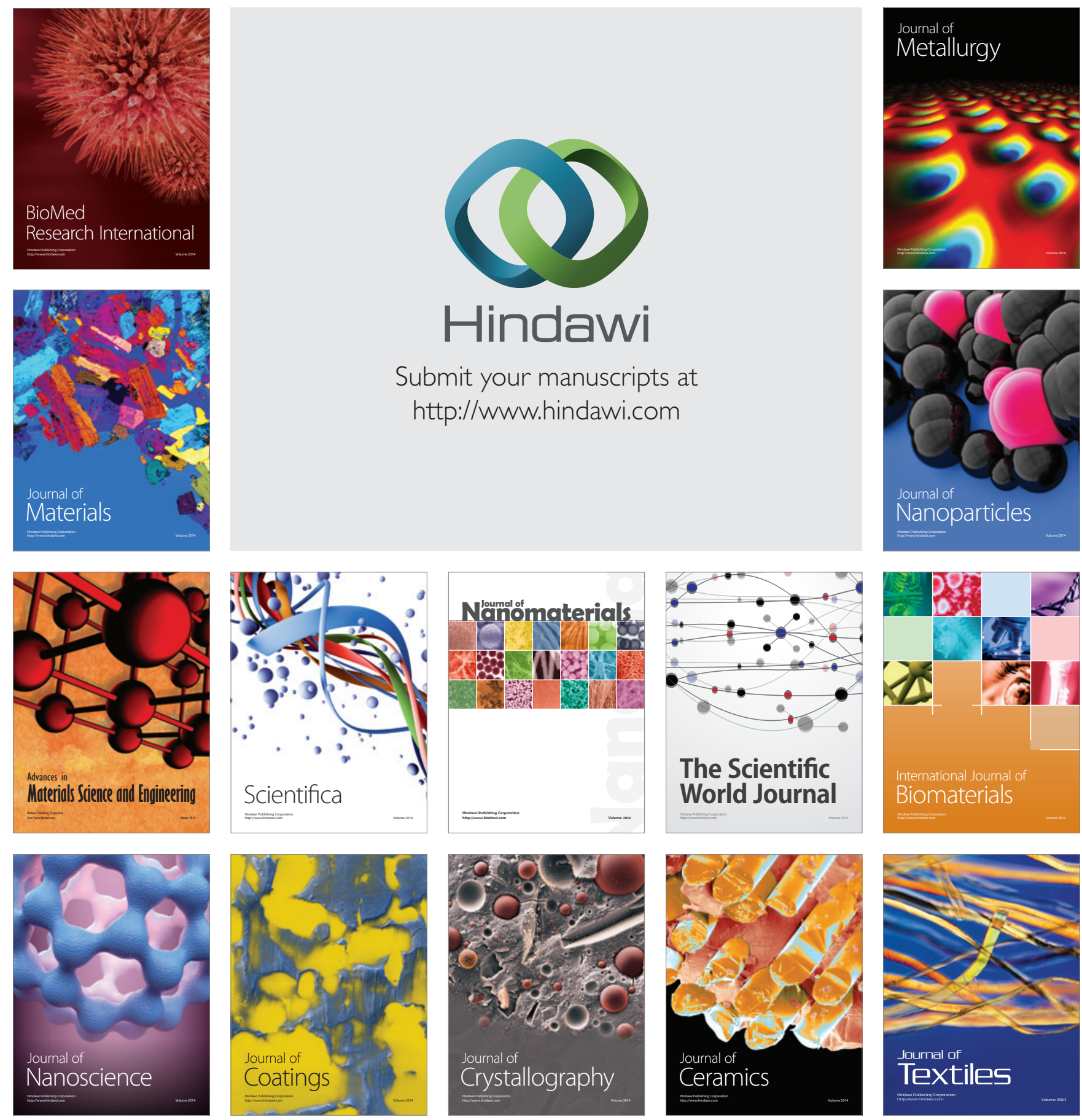